\title{
Robust Grain Supply Chain Design Considering Post-Harvest Loss and Harvest Timing Equilibrium
}

\begin{abstract}
This paper presents a bi-level robust optimization model, where a food company maximizes its profit and minimizes post-harvest loss by optimally deploying grain processing/storage facilities and determining grain purchase price, while a group of spatially distributed non-cooperative farmers determine harvest time, shipment, storage, and market decisions under yield uncertainty and market equilibrium. The non-cooperative behavior of the food company and the farmers is represented by a bilevel Stackelberg leader follower's game model with mixed-integer decision variables. The proposed model and solution approach are applied to case studies for Illinois and Brazil.
\end{abstract}

Keywords: Post-harvest loss, Robust optimization, Grain supply chain, Market equilibrium, Bottleneck model

\section{INTRODUCTION}

Post-harvest loss (PHL) for grain crops occurs through various stages of post-harvest operations, starting from the time of harvest and ending at human consumption. PHL includes both the quantity loss and quality loss during transportation, storage and processing. Quantity loss is measured as weight or volume reduction caused by grain respiration, drying and spillage, whereas quality loss is concerned with the decrease of product value (often resulting in price reduction or even loss in sales opportunity). According to U.N. Food and Agriculture Organization (FAO), 1.3 billion tons of food are wasted or lost worldwide per year. PHL differs by grain types and regions, ranging up to $10 \%$ of the total grain output in developed countries (Gustavsson et al., 2011), and up to 20\% in developing countries (Zorya et al., 2011). Reduction in PHL would enhance global food security, which is a growing concern due to the high food prices caused by growing population and increasing demand for industrial uses such as biofuel.

The high PHL value is partially due to poor storage conditions and insufficient storage facilities. For example, Brazil, the fourth largest agricultural producer in the world, is growing into a bigger player in global grain sales. As the world's No. 1 soybean producer and exporter, Brazil increased its annual soybean export by an additional 2.0 million tons in 2015/2016 (to a total of 56.5 million tons), reflecting an increase in exportable supplies and growing competitiveness (Rubio, 2015). Reducing PHL in Brazil, therefore, is not only important to its own agricultural and economic development but also crucial to global food security. However, grain storage facilities in this country face extremely high pressure to keep up with the increasing production. Brazil has a current storage capacity at $75 \%$ of grain production, far short of the ideal target of $120 \%$ (as recommended by FAO). The lack of storage infrastructures compels all farmers to ship out their grains right in the harvest season, which causes severe congestion at export ports and elevators. In 2013, the storage overflow led to a 40-mile lineup of trucks waiting to unload soybeans/corns outside Santos Ports and various rail terminals at Araguaia, Brazil (Stewart, 2013). The agricultural products in these trucks spent up to two weeks of waiting time before they can be unloaded, which, under the humid and hot weather in Brazil, aggravates the degradation of grain quality and pushes up the extent of post-harvest loss. Similar problems exist in the developed world as well. European Union 
(EU), the top wheat export market in the world, has bottlenecks in storage infrastructures that have imposed difficulty in keeping up with the rising agricultural productivity (The Crop Site, 2014).

The lack of storage infrastructure and concentration of shipment demand lead to higher logistics costs during the harvest season. This in turn influences the farmers' harvest timing decisions, as well as PHL. According to a survey conducted by FAO (Grolleaud, 2002), grain harvest time is another critical factor that affects post-harvest losses. Normally, grain harvest time is determined by the degree of maturity. Harvesting grains before maturity leads to large weight reduction and high moisture content, and this makes the grains unsuitable for storage and preservation. Harvesting late after maturity, on the other hand, ensures good field drying but entails the risks of quantity losses caused by rodents, insects, and molds. Over-drying also increases the risks of cracking during milling, which degenerates the grains' quality. Indeed, there exists a best grain harvest time that the farmers wish to follow. However, due to limited port loading speed and insufficient on-farm storage, the ports could become congested quickly if all farmers harvest and ship their grains to the ports at the same time. The farmers have to make compromises regarding the best harvest timing so as to balance the tradeoffs between the PHL and the excessive waiting time at ports. Moreover, in tropical regions, harvesting one type of grains is usually immediately followed by the planting of another type, which imposes a strict completion deadline on the earlier harvest (Cordonnier, 2015). The presence of distinct dry/rainy seasons also imposes tight restrictions on the available time window for harvesting. In extreme cases, the farmers could completely miss the opportunities of harvesting the current crops and planting for the next season if they start harvesting too late and get trapped in consecutive rainy days. The Progressive Farmer by DTN once reported a story about farmers in Brazil having no choice but to let soybean rot in the fields owing to bad harvest timing decisions (Stewart, 2013). Choosing harvest time wisely is thus critical for farmers to reduce the PHL as well as the port congestion cost due to the fragile logistic system.

The Brazilian government has recognized the storage deficit as the major obstacle in its grain logistics systems, and they have initiated a five-year-program of Storage Construction and Amplification to address the problem (Cordonnier, 2014). The program provides a total of $\mathrm{R} \$ 5$ billion low interest loans per year for agricultural storage facilities construction from 2013 to 2018. Additional storage capacity will not only substantially decrease the PHL during transportation but also maintain the marketing flexibility for both farmers and food companies. It shall be noted that the pressing need for storage capacity is not unique to Brazil, it also occurs in other countries (Zorya et al., 2011; Ramaswami, 2013). The government of the Punjab State in India plans to add 2.5 million metric tons of capacity to its current modern storage system with temperature-controlled steel grain silos (Sharon et al., 2014). The Swiss Agency for Development and Cooperation has initiated an Effective Grain Storage Project to promote the implementation of metal silos in Sub-Saharan Africa (International Maize and Wheat Improvement Center, 2012). In Europe, Rabobank and Copa-Cogeca urge the EU to prioritize projects on improving grain storage capacity into the 315 billion euros Investment Plan (The Crop Site, 2014). The impending large-scale investment in storage system calls for careful planning of the facility location and logistics channels, which not only directly influences the sustainability of agricultural business in these countries, but also has far-reaching impacts on global food security and economic stability.

Although post-harvest loss is less severe in developed countries, intensifying impacts of climate change and the resulted disasters (e.g., drought, flooding) have increased crop yield uncertainty and have put global food security at risk. The recent prolonged drought in Alberta, Canada is said to force grain 
production to drop by 25-30\% in 2015 (Tucker, 2015). Flooding in Indiana, U.S., has destroyed 5\% of its corn and soybean crops since June, 2015 (Pack and Robinson, 2015). Hurricanes, tornados and other nature disasters are also frequently reported in recent years. These pressing issues call for robust design of storage facility locations to deal with crop yield fluctuations. A few pioneering studies have addressed such intrinsic uncertainties in supply chain networks (Cardona-Valdes et al., 2014; Borodin et al., 2014; Ahumada and Villalobos, 2009; Allen and Schuster, 2004; Li and Ouyang, 2010). Another challenge stems from the complex interactions between the grain companies and spatially distrusted farmers. This paper considers a food company which plans to penetrate into the grain storage/processing market. The existing storage/processing facilities (e.g., those owned by a third party) compete with the food company for grain supply, while each farmer aims at maximizing its own profit by determining where to sell their grains. This company must hence consider the presence of existing competitors and the non-cooperative farmers while determining its facility deployment and grain purchase prices. These interactions naturally lead to an equilibrium when every stakeholder (e.g., farmer, food company) can longer increase its profit by changing its decisions unilaterally. This type of problem is often modeled in the form of bi-level programs (Bai et al., 2012; Wang et al., 2013; Wang et al., 2015), and more details can be found in the literature review section. Although these two challenges have been extensively studied in the literature, few efforts have been made to address them simultaneously. This research is sponsored in part by a leading international corporation for food processing and commodity trading. We have a strong interest in reducing world-wide post-harvest loss from the lack of infrastructure and management. Grain productions and exports in Brazil are growing rapidly in recent years, and Brazil has become the No. 1 soybean exporter in the world. It will be an intriguing question to investigate how we shall build additional storage/processing facilities under competition with the existing agricultural supply chain systems.

In light of these challenges, this paper studies a strategic grain processing/storage facility location problem from the perspective of a food company, with a particular focus on reducing PHL considering stochastic crop yield and marketing equilibrium among farmers. A food company aims at maximizing its profit by optimally deploying grain processing/storage facilities and determining grain purchase prices, while a group of spatially distributed non-cooperative farmers determine their individual harvest time, shipment, storage, and market outlet decisions. We assume the farmers are independent and do not build alliance with the food company. A bi-level Stackelberg leader-followers game is formulated to capture the interactions among the food company and the multiple farmers. In the upper level, two types of strategies for the food company (i.e., risk averse and risk seeking) are modeled respectively in order to investigate the effects of such strategies on storage facility location, company's profit, farmers' profit and PHL. In the lower level, multiple non-cooperative farmers compete for resources and access to markets, and harvest time equilibrium models are developed considering harvest ending time boundaries. Closedform formulas are derived for the generalized cost at equilibrium, which consists of those for transportation and PHL. Karush-Kuhn-Tucker (KKT) conditions are derived to reformulate the bi-level problems into equivalent single-level problems (with complementarity constraints) that are solved by customized Lagrangian relaxation approaches. Further, the models are complicated by the incorporation of uncertain crop yields. By assuming that stochastic crop yields are contained in a polyhedral uncertainty set, and by linearizing the constraints associated with stochastic yields through the dual problem, we 
utilize robust optimization techniques to reduce the original stochastic problem into a tractable deterministic one.

The remainder of the paper is organized as follows: Section 2 introduces the related literature on facility location problem, risk management, and market equilibrium modeling. Section 3 presents the models and solution algorithms when the food company is respectively risk averse and risk seeking. Section 4 applies the proposed models and solution algorithms to an Illinois case and a Brazil case. Section 5 provides the conclusions and possible future directions of research.

\section{LITERATURE REVIEW}

The facility location problem (FLP), or more generally the supply chain network design problem, has been extensively studied in the past decades. One may refer to Daskin (1995), Meixell and Gargeya (2005), Ahumada and Villalobos (2009), Melo et al. (2009) for recent reviews. Researchers also combined the facility location problem with other considerations (e.g., transportation mode, infrastructure, routing, and inventory) into more realistic yet complex problems. Indeed, a large body of extensions to the basic FLP can be found in the literature. Bai et al. (2011) investigated biofuel refinery location and product shipment routing problem in a congested transportation network. Hajibabai and Ouyang (2013) studied biofuel refinery location in multi-modal transportation networks where highway/railroad link expansion is possible. Hajibabai et al. (2014) further proposed a mixed integer non-linear program to jointly optimize the freight facility location, freight shipment routing and pavement infrastructure rehabilitation. Ahmadi-Javid and Azad (2010) incorporated location, routing and inventory decisions in supply chain network design. In addition, PHL as a crucial and unique component in grain supply chains further complicates the facility location problem we are facing. Blackburn and Scudder (2009) discussed supply chain management for perishable products such as melon and corn. Apaiah and Hendrix (2005) proposed a mixed integer program to design a supply chain network for pea-based protein foods. However, they did not consider crop yield uncertainty or farmers' marketing options as part of the supply chain design. In light of the computation difficulties residing in FLP, which is typically NP-hard, researchers have developed different algorithms to solve them. For example, Bai et al. (2011) and Park et al. (2010) applied Lagrangian Relaxation approach and sub-gradient method to update lower bound and upper bound iteratively until a desirable gap was reached. Cardona-Valdes et al. (2014) applied Tabu search to select warehouse location and transportation mode for a two echelon supply network. Other methods include decomposition and simulated annealing (Ahmadi-Javid and Seddighi, 2013), genetic algorithm (Hajibabai and Ouyang, 2013) and piecewise linearization technique (Baghalian et al., 2013).

Recently, a renewed stream of research on incorporating risk management into FLP to deal with the uncertainties in demand, price and facility operation has gained a lot of attention. There are two forms of risks: operational risk and disruptions. Operational risks stem from the intrinsic uncertainties such as customer demand and product quantity, which influence the daily performance of supply chain networks (Cardona-Valdes et al., 2014; Park et al., 2010). Disruption risks caused by natural disasters may lead to partial or complete malfunction of facilities in a logistics network (Vahdani et al., 2012; Cui et al., 2010; Li and Ouyang, 2010). Two methods are typically used to deal with the uncertainties involved in the FLP, namely, robust optimization and stochastic program. Robust optimization focuses on minimizing system cost under the worst case scenario and is formulated as a min-max problem (Ahmadi-Javid and Seddighi, 2013; Ben-Tal et al., 2011; Ben-Tal et al., 2006). Stochastic parameters are confined in a specified 
uncertainty set and the optimal solution must be feasible for all parameter realizations within the uncertainty set, which can take various forms, such as box, polyhedral, and elliptical uncertainty sets. The robust model has a similar computational complexity as its deterministic counterpart. The downside is it often generates pessimistic solutions and provides overprotection. Stochastic optimization assumes a fixed distribution pattern of stochastic parameters and minimizes the cost expectations (Ruszczynski, 2008; Higle and Sen, 1996). Since it is generally difficult to derive closed-forms for the expectation terms, people often turn to approximation method, such as sample average, which could lead to great computation difficulties. Unlike the scenario based stochastic programming, another group of studies assumes predetermined failure probabilities, either independent or correlated among facilities, and is capable of formulating the problem as a compact integer linear program (Cui et al., 2010; Li et al., 2013; Xie et al., 2015).

Another important extension of FLP captures non-cooperative behavior of individual stakeholders (e.g. customers, business owner). This type of problem is often addressed in the form of bi-level programs or equilibria, and is typically referred as a mathematical program with equilibrium constraints (MPEC). Bai et al. (2012), Wang et al. (2013) and Wang et al. (2015), for example, studied biofuel supply chain design under feed stock market equilibrium and modeled the problem as bi-level Stackelberg-Nash leader-follower games. The market equilibrium was generally represented by a set of complementarity constraints based on KKT conditions.

Despite all these efforts, very few studies have simultaneously considered system stochasticity, spatiotemporal equilibrium, and non-cooperative behavior in the context of grain supply chain design. To the authors' best knowledge, existing studies are limited to service network design with stochastic demand and equilibrium traffic flows (An and Lo, 2014a; 2014b; An and Lo, 2015). Equilibrium flows were either realized by solving a traffic assignment problem or represented by a set of variational inequality constraints. This paper, in contrast, proposes a new model which simultaneously optimizes storage facility location, grain procurement price, harvest time, and market decisions of multiple supply chain players, while PHL, stochastic crop yield, service congestion and market equilibrium are considered.

\section{MODEL FORMULATION}

We study a three-echelon supply chain network for a single type of grain commodity from the perspective of the food company. The network consists of sets of spatially-distributed farmers $I$, existing local elevators $K$, company-owned processing/storage facilities (PSF) $J$, and export ports $M$. Farmer $i \in I$ produces a stochastic amount of crop yield $D_{i}$ each year. Due to a lack of on-farm storage, farmers have three marketing options during the harvest season: selling their products directly to export port $m \in M$, to local elevator $k \in K$, or to PSF $j \in J$. The existing local elevators belong to an outside party and are capable of grain processing, storage and etc. As the representative of the food company, further marketing decisions of elevators (when, where and how to sell the purchased grains) are beyond our decisions and thus are not modeled in this paper. The export ports are the final markets of the investigated grain supply chain. Each elevator $k$ has a storage capacity of $S_{k}$ million bushels (mbu.) and procures grains from farmers at a price of $p_{k} \$ /$ bushel. Construction of a PSF at $j$ requires a prorated yearly investment of $c_{1}^{j}$, but will be able to store $S_{j}$ mbu. of grains and undertake multiple processing operations (such as cleaning and drying) at a unit processing cost of $c_{2}^{j}$ per bushel. In this work, we assume the export ports are the 
final markets with infinite capacity, i.e. the ports can absorb all productions from the farmers. At export ports, grains without processing are priced at $p_{m 1}$ per bushel, and the price is increased to $p_{m 2}$ per bushel after processing. We assume the unit transportation cost is $c_{3} \$ /$ bushel ${ }^{*} \mathrm{~km}$ during the harvest season but $\hat{c}_{3} \$ /$ bushel*km during the off seasons. The unprocessed and processed grains have different PHL rates during transportation (e.g., due to spillage and respiration): $c_{4} \% / \mathrm{km}$ and $\hat{c}_{4} \% / \mathrm{km}$ respectively, with $c_{4}>\hat{c}_{4}$. PHL also occurs during processing, at a fixed rate of $\tilde{c}_{4}$ percent at all PSFs. The grain production cost is $c_{5} \$ /$ bushel. Each port is able to load grains onto ships at a limited rate of $s$ mbu./day. Congestion may occur at ports, and in such cases, incoming trucks wait in queue and grain degradation continues. We use $c_{0}^{m}$ (\$/ bushel*day) to denote the generalized port congestion cost which is composed of the PHL cost and the additional truck holding cost (can be regarded as transportation cost). Farmers pay the transportation cost and the PHL cost along the transportation routes originating from farmlands to the point of sales. The food company pays grain processing and shipment cost from PSFs to ports.

Given the locations of famers, existing local elevators, and export ports, and the competing prices, the food company wishes to determine whether to locate a PSF at each candidate location $j \in J$. Binary variable $Y_{j}$ equals 1 if a PSF is constructed at $j$ or 0 otherwise. PSFs are constructed before the stochastic crop yields are realized, and their locations cannot be altered during their service lives. At the same time, the food company determines the grain purchase price $p_{j}, \forall j \in J$, to facilitate its decision on PSF deployment. Given the locations of existing local elevators, PSFs, and ports as well as the grain purchase prices, farmers determine how to transport and sell grains to these three markets, which can be specified by variables $\mathbf{x}_{\mathbf{I J}}=\left\{x_{i j}, i \in I, j \in J\right\}, \mathbf{x}_{\mathbf{I K}}=\left\{x_{i k}, i \in I, k \in K\right\}$, and $\mathbf{x}_{\mathbf{I M}}=\left\{x_{i m}, i \in I, m \in M\right\}$. After grain processing, the food company sells the processed grains to the ports in off seasons such that they can evade the port congestion. The volumes of grains sold are specified by variables $\mathbf{x}_{\mathbf{J M}}=\left\{x_{j m}, j \in J, m \in M\right\}$. Let $l_{i j}, l_{i k}$ and $l_{i m}$ denote the distances from farmer $i$ to PSF $j \in J$, local elevator $k \in K$, and port $m \in M$, and let $l_{j m}$ denote the distance from PSF $j$ to port $m$. We assume independent and perfectly competitive markets at the existing elevators and the ports, with their grain purchase prices endogenously determined by linear inverse demand functions; i.e.,

$$
p_{k}=b_{k}-a_{k} * \sum_{i \in I} x_{i k} \quad \forall k \in K,
$$

$$
p_{m 1}=b_{m 1}-a_{m 1} * \sum_{i \in I} x_{i m} \quad \forall m \in M,
$$

(1)

$$
p_{m 2}=b_{m 2}-a_{m 2} * \sum_{j \in J} x_{j m} \forall m \in M,
$$

where $b_{k}, a_{k}, b_{m 1}, a_{m 1}, b_{m 2}$ and $a_{m 2}$ are constant parameters, and the initial price of the processed grains is higher than that of the unprocessed ones, $b_{m 2}>b_{m 1}$. These sets of prices are denoted by $\mathbf{p}_{\mathbf{k}}=\left\{p_{k}, k \in K\right\}, \mathbf{p}_{\mathbf{m} 1}=\left\{p_{m 1}, m \in M\right\}$, and $\mathbf{p}_{\mathbf{m} 2}=\left\{p_{m 2}, m \in M\right\}$.

While planning its infrastructure, the company assumes that the stochastic crop yields $D_{i}, \forall i \in I$, 4 fluctuate within a predetermined uncertainty set 


$$
U \equiv\left\{\mathbf{D}: D_{i} \in\left[\overline{d_{i}}-d_{i}, \bar{d}_{i}+d_{i}\right], \forall i, \sum_{i \in I} \frac{\left|D_{i}-\overline{d_{i}}\right|}{d_{i}} \leq \Gamma\right\} .
$$

This type of uncertainty set is commonly seen in the robust optimization literature (e.g., Bertsimas and

3 Thiele, 2006). Each stochastic crop yield $D_{i}$ is bounded in an interval centered at a nominal value $\bar{d}_{i}$ and half length $d_{i}$. Since it is unlikely that all stochastic yields reach their worst-case values simultaneously, the company incorporates a deviation "budget" constraint in the uncertainty set; i.e., the total normalized deviations $\sum_{i \in I}\left|D_{i}-\overline{d_{i}}\right| / d_{i}$ cannot exceed the budget of $\Gamma$. Obviously, when $\Gamma=0$, the problem degenerates to a deterministic one; or else if $\Gamma=|I|$, the worst-case deviation could occur at all farms. The company can choose different $d_{i}$ and $\Gamma$ to quantify its robustness level and examine its effect on the PSF network configuration. The three echelon grain supply chain can be summarized in Fig. 1.

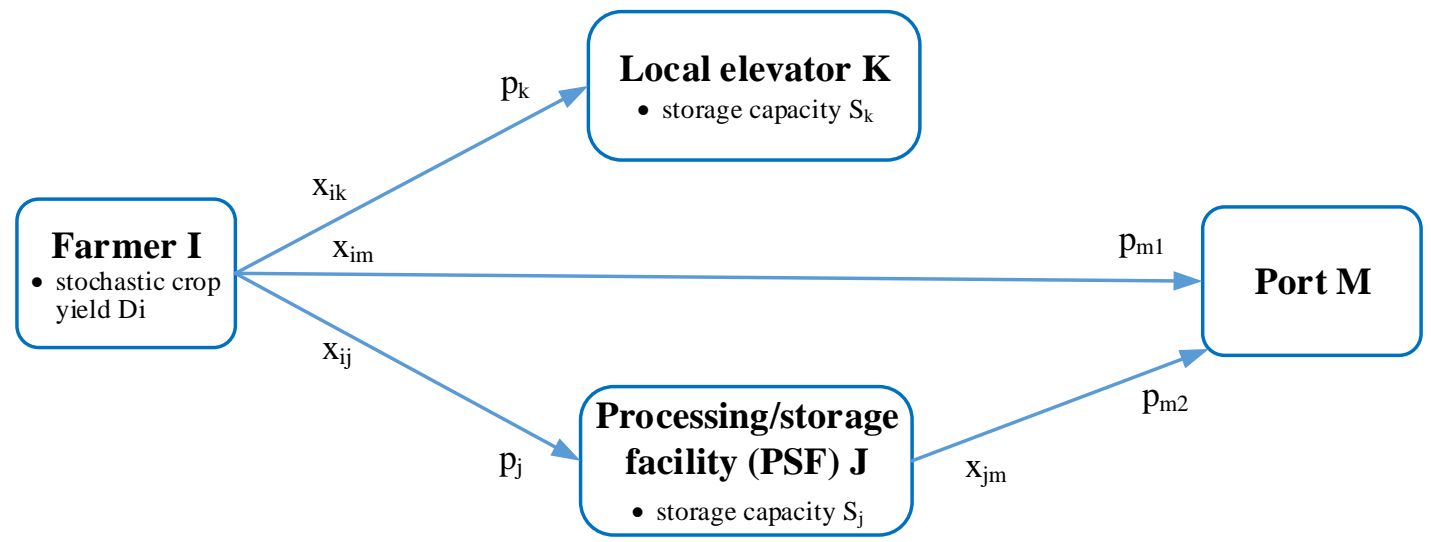

Fig. 1 Flow chart of the grain supply chain

Additionally, we assume that only one transportation mode, i.e. trucking, is considered -- trucks are still the most common means of grain transportation (Bai et al., 2011). Next, a harvest time equilibrium model needs to be first established to derive the generalized port congestion cost $c_{0}^{m}$.

\subsection{Generalized Port Congestion Cost}

In this section, we borrow the idea of bottleneck models (Yang et al., 2013; Arnott et al., 1991) to study harvest time equilibrium among multiple competing farmers. We focus on a particular port bottleneck $m$ where various farmers experience excessive queuing time. We assume for simplicity a common preferred harvest time $t^{*}$, and an equal transportation time from all the farms to the port ${ }^{1}$. To mitigate the congestion at the port, farmers consider alternative grain harvest times that may incur some earliness or lateness penalty. Let $\alpha, \beta$ and $\gamma$ ( $\$ /$ bushel*day) be the unit waiting cost at ports, the early harvest penalty, and late harvest penalty, respectively. We assume the unit waiting cost (consisting of both PHL

\footnotetext{
${ }^{1}$ This assumption is often reasonable as the free-flow travel time is generally marginal as compared with the queueing time at the port. Moreover, our primary goal of examining the impact of port congestion on harvest timing exempts this simplification from significantly influencing the resultant equilibrium. In general, this assumption can be relaxed by defining a "wished" cumulative arrival curve at the port which takes into consideration free-flow travel time from farms to port; see the Vickrey model (1969) for some discussion.
} 
and truck holding expenses) is larger than the early/late penalties (PHL only), i.e., $\alpha \geq \beta, \alpha \geq \gamma$. The total

2 amount of grains shipped to the port in a season is denoted by $N=\sum_{i \in I} x_{i m}$. Let $\bar{t}$ be harvest ending time

3 deadline. In practice, however, this deadline may or may not be binding depending on the nature of the

4 deadline, the natural climate, and the number of farmers involved in the equilibrium. Intuitively, if $\bar{t}$ is

5 large enough, then this deadline will not affect the harvest time equilibrium. For example, in Illinois, corn

6 is usually harvested in October, well before the arrival of the snowfall (around early December). There is

7 sufficient harvest time for farmers in Illinois and no deadline is likely to be binding. On the other hand, in

8 the case of soybean harvest in Brazil, the number of farmers is sufficiently large, the harvest delay is

9 sufficiently extensive, and the start of the rainy season is so close to the soybean harvest season, the

10 harvest deadline $\bar{t}$ is often found to be binding.

11 First we study the simpler special case when $\bar{t}$ is large. It turns out that there is a critical harvest

12 ending time, $t_{e}=t^{*}+\frac{\beta}{\beta+\gamma} \frac{N}{s}$, such that any $\bar{t}$ satisfying $\bar{t} \geq t_{e}$ will not affect the harvest time

13 equilibrium. In this case, the generalized cost at equilibrium is given in Lemma 1.

14

15 Lemma 1. If $\bar{t} \geq t_{e}=t^{*}+\frac{\beta}{\beta+\gamma} \frac{N}{s}$, the harvest time equilibrium is achieved when grain arrival rate is $16 r_{1}=\frac{\alpha+\beta}{\alpha} s$ for $t<t^{*}$ and $r_{2}=\frac{\alpha-\gamma}{\alpha} s$ for $t \geq t^{*}$. The generalized port congestion cost at equilibrium is $17 \quad \frac{\beta \gamma}{\beta+\gamma} \frac{N}{s}$.

18

Proof: See the Appendix.

20

When $\bar{t}$ satisfies $\bar{t}<t_{e}=t^{*}+\frac{\beta}{\beta+\gamma} \frac{N}{s}$, however, all grains should be harvested and shipped out by

$22 \bar{t}$. The main results are summarized in the following Proposition.

24 Proposition 1. If $\bar{t}<t_{e}=t^{*}+\frac{\beta}{\beta+\gamma} \frac{N}{s}$, the harvest time equilibrium is achieved when grain arrival rate 25 remains $r_{1}=\frac{\alpha+\beta}{\alpha} s$ for $t<t^{*}$ and $r_{2}=\frac{\alpha-\gamma}{\alpha} s$ for $t \geq t^{*}$. The generalized port congestion cost at 26 equilibrium however becomes $c_{0}^{m}(N, \bar{t})=\frac{\alpha \beta}{(\alpha+\beta)} \frac{N}{s}-\frac{\beta(\alpha-\gamma)\left(\bar{t}-t^{*}\right)}{(\alpha+\beta)}$.

27

28 Proof: See the Appendix. 
It can be easily verified that when $\bar{t} \rightarrow t_{e}=t^{*}+\frac{\beta}{\beta+\gamma} \frac{N}{s}, c_{0}^{m}(N, \bar{t})$ reduces to the one in Lemma 1.

Now we are ready to introduce our robust models for risk-averse and risk-seeking companies, respectively.

\subsection{Risk-averse Food Company}

Most privately owned companies can be probably considered as risk averse. Such a company determines

facility locations $\mathbf{Y}=\left\{Y_{j}, j \in J\right\}$ and grain purchase prices $\mathbf{p}_{\mathbf{J}}=\left\{p_{j}, j \in J\right\}$ to maximize its total profit under the worst case scenario in its chosen uncertainty set. The farmers are price takers and make decisions individually to maximize their individual profits. A bi-level Stackelberg leader-followers game $\mathbf{P 1}$ is formulated to capture the interactions among the food company and the farmers.

\section{(P1)}

(P1-1) Upper level:

$$
\underset{\mathbf{x}_{\mathbf{J M}}, \mathbf{Y}, \mathbf{p}_{\mathbf{J}}, \mathbf{p}_{\mathbf{m} 2}}{\operatorname{Max}} \sum_{j \in J} \sum_{m \in M} x_{j m} p_{m 2}\left(1-\hat{c}_{4} l_{j m}-\tilde{c}_{4}\right)-\sum_{j \in J} \sum_{m \in M} x_{j m}\left(p_{j}+c_{3} l_{j m}+c_{2}^{j}\right)-\sum_{j \in J} c_{1}^{j} Y_{j}
$$

s.t. (3) and

$$
\begin{aligned}
& Y_{j} \in\{0,1\} \forall j \in J \\
& \sum_{m \in M} x_{j m}=\sum_{i \in I} x_{i j}\left(1-c_{4} l_{i j}\right) \quad \forall j \in J
\end{aligned}
$$

where $x_{i j}, j \in J$, satisfies (1), (2) and (7)-(10) below for each farmer $i \in I$,

(P1-2) Lower level:

$$
\begin{aligned}
\underset{\left\{x_{i j}, \forall j \in J\right\},\left\{x_{i k}, \forall k \in K\right\},\left\{x_{i m}, \forall m \in M\right\}, \mathbf{p}_{\mathbf{k}}, \mathbf{p}_{\mathbf{m} 1}}{\operatorname{Max}} & \sum_{k \in K}\left[p_{k}\left(1-c_{4} l_{i k}\right)-c_{3} l_{i k}\right] x_{i k}+\sum_{j \in J}\left[p_{j}\left(1-c_{4} l_{i j}\right)-c_{3} l_{i j}\right] x_{i j} \\
& +\sum_{m \in M}\left[p_{m 1}\left(1-c_{4} l_{i m}\right)-c_{3} l_{i m}-c_{0}^{m}\right] x_{i m}-c_{5} \bar{d}_{i}
\end{aligned}
$$

s.t. (1), (2) and

$$
\sum_{k \in K} x_{i k}+\sum_{m \in M} x_{i m}+\sum_{j \in J} x_{i j} \leq D_{i}, \forall \mathbf{D} \in U
$$

$$
\sum_{i \in I} x_{i k} \leq S_{k} \quad \forall k \in K \quad \leftarrow \mu_{k}
$$

$$
\sum_{i \in I} x_{i j} \leq S_{j} Y_{j} \quad \forall j \in J \quad \leftarrow \rho_{j}
$$

The upper-level objective function (4) captures the food company's total profit, including the total revenue minus the PHL during transportation and processing, the variable cost for grain procurement, processing, and transportation from PSFs to ports, and the capital cost for PSF construction. Constraints (5) define binary location decisions. Constraints (6) impose grain conservation at all $j \in J$. In the lower level, objective function (7) includes farmer $i$ 's total profit from sales to the local elevators, the food company, and the ports, minus the respective costs due to PHL, transportation, port congestion and production. Cost $c_{0}^{m}$ in the last bracket is derived from Proposition 1. Constraints (8) ensure that the 
1 amount of grains sold by farmer $i$ cannot exceed the stochastic crop yield $D_{i}$, which is defined by the

2 uncertainty set $U$. Constraints (9) and (10) are capacity constraints for the existing elevators and PSFs.

$3 \quad \mu_{k}$ and $\rho_{j}$ are the Lagrangian multipliers associated with constraints (9) and (10).

Note that $\mathbf{P 1}$ is a bi-level non-linear model with parameters defined over the uncertainty set, and it 5 is quite challenging to solve. In the following subsections, we first propose a way to transform P1 into a 6 single-level deterministic problem.

\section{$7 \quad$ 3.2.1 Transformation}

8 Constraints (8) cover all possible crop yield realizations $\left\{D_{i}, i \in I\right\}$ in the uncertainty set $U$. We instead 9 consider the worst case scenario associated with (8). Equivalently, we aim at determining the smallest 10 yield combination $\left\{D_{i}, i \in I\right\}$ in $U$, which still satisfies $\sum_{k \in K} x_{i k}+\sum_{m \in M} x_{i m}+\sum_{j \in J} x_{i j} \leq D_{i}, \forall i \in I$. Namely,

$11 \min \underset{\left\{D_{i}, \forall i\right\} \in U}{D_{i}} \geq \sum_{k \in K} x_{i k}+\sum_{m \in M} x_{i m}+\sum_{j \in J} x_{i j}, \forall i \in I$. Let $Z_{i} \triangleq\left(D_{i}-\overline{d_{i}}\right) / d_{i}$, and we can obtain $D_{i}=\overline{d_{i}}+Z_{i} d_{i}$. To this end, we have to solve the auxiliary primal problem for each $i \in I$ :

Primal: $\min \bar{d}_{i}+Z_{i} d_{i}$ s.t. $\sum_{i \in I}\left|Z_{i}\right| \leq \Gamma,\left|Z_{i}\right| \leq 1$.

In the primal problem, $\bar{d}_{i}$ and $d_{i}$ are positive. Hence the optimal $Z_{i}$ must be non-positive so as to minimize the objective function. Let $z_{i}=\left|Z_{i}\right|$, the primal problem becomes: $\min \bar{d}_{i}-z_{i} d_{i}$ s.t. $\sum_{i \in I} z_{i} \leq \Gamma, 0 \leq z_{i} \leq 1$. Let $q$ and $r_{i}$ be the dual variables associated with the two constraints and the dual problem is:

Dual: $\max \overline{d_{i}}-q \Gamma-r_{i}$ s.t. $q+r_{i} \geq d_{i}, q \geq 0, r_{i} \geq 0$.

According to the strong duality theory, the primal and its dual achieve the same objective value at optimum. The constant $\bar{d}_{i}$ is incorporated in the objective functions for ease of understanding - its presence will not affect the optimal solutions. The objective of constraint (8) changes from finding the minimum $D_{i}$ that is still larger than $\sum_{k \in K} x_{i k}+\sum_{m \in M} x_{i m}+\sum_{j \in J} x_{i j}$ to finding the maximum $\bar{d}_{i}-q \Gamma-r_{i}$ that is larger than $\sum_{k \in K} x_{i k}+\sum_{m \in M} x_{i m}+\sum_{j \in J} x_{i j}$. The transformation allows us to directly add the dual problem to P1-2. Constraints (8) are hence replaced by the following set of linear constraints:

$$
\sum_{k \in K} x_{i k}+\sum_{m \in M} x_{i m}+\sum_{j \in J} x_{i j} \leq\left(\bar{d}_{i}-q \Gamma-r_{i}\right) \leftarrow \lambda_{i}
$$

(1)

$$
\begin{aligned}
& q+r_{i} \geq d_{i} \quad \leftarrow \theta_{i} \\
& q \geq 0, r_{i} \geq 0
\end{aligned}
$$

where $\lambda_{i}$ and $\theta_{i}$ denote the associated Lagrangian multipliers. 
The farmers share the coupled capacity constraints (9) and (10) as well as the common external variable $q$. The lower-level optimization problem aims at determining a Nash Equilibrium solution such that no farmer can improve its profit by changing market decisions $\left\{x_{i j}, \forall j \in J\right\},\left\{x_{i k}, \forall k \in K\right\},\left\{x_{i m}, \forall m \in M\right\}$ unilaterally, while satisfying the coupled constraints. In this section, we derive the KKT conditions that equivalently represent the optimal solution to farmer i's optimization problem P1-2. For ease of understanding, the Lagrangian multiplier associated with each constraint is shown on the right hand side of the arrows in constraints (9)-(12). Each farmer $i$ has its own complementary constraints in (14)-(20) and all farmers share the common capacity constraints (21)-(22). For example, $0 \leq a \perp b \geq 0$ represents a complementarity constraint $a^{*} b=0, a \geq 0, b \geq 0$. Since all farmers' KKT conditions have the same structure, we simply add $\forall i \in I$ to the end of each complementary constraint in (14)-(20) for convenience.

(1)

16

17

8

9

(1)

$$
\begin{aligned}
& 0 \leq x_{i k} \perp-p_{k}\left(1-c_{4} l_{i k}\right)+c_{3} l_{i k}-a_{k}\left(1-c_{4} l_{i k}\right) x_{i k}+\lambda_{i}+\mu_{k} \geq 0 \quad \forall k \in K, i \in I \\
& 0 \leq x_{i j} \perp-p_{j}\left(1-c_{4} l_{i j}\right)+c_{3} l_{i j}+\lambda_{i}+\rho_{j} \geq 0 \quad \forall j \in J, i \in I
\end{aligned}
$$$$
0 \leq x_{i m} \perp-p_{m 1}\left(1-c_{4} l_{i m}\right)+c_{3} l_{i m}+c_{0}^{m}-a_{m 1}\left(1-c_{4} l_{i m}\right) x_{i m}+\frac{\partial c_{0}^{m}}{\partial x_{i m}} x_{i m}+\lambda_{i} \geq 0, \forall m \in M, i \in I
$$$$
0 \leq r_{i} \perp-\theta_{i}+\lambda_{i} \geq 0 \quad \forall i \in I
$$$$
0 \leq q \perp-\theta_{i}+\Gamma \lambda_{i} \geq 0 \quad \forall i \in I
$$$$
0 \leq \lambda_{i} \perp \bar{d}_{i}-q \Gamma-r_{i}-\sum_{k \in K} x_{i k}-\sum_{m \in M} x_{i m}-\sum_{j \in J} x_{i j} \geq 0 \quad \forall i \in I
$$$$
0 \leq \theta_{i} \perp q+r_{i}-d_{i} \geq 0 \quad \forall i \in I
$$$$
0 \leq \mu_{k} \perp S_{k}-\sum_{i \in I} x_{i k} \geq 0 \quad \forall k \in K
$$$$
0 \leq \rho_{j} \perp S_{j} Y_{j}-\sum_{i \in I} x_{i j} \geq 0 \quad \forall j \in J
$$

Existence of an equilibrium solution can be guaranteed if it satisfies the KKT conditions (Bai et al., 2016). After the reformulation, the robust bi-level problem is reduced to a single-level deterministic problem with complementarity constraints, which can be solved by existing commercial solvers such as Knitro (Wang et al., 2013). This type of problem is regarded as discretely constrained mathematical problem with equilibrium constraints (DC-MPEC), which is summarized as follows:

$$
\text { (P2) } \underset{\mathbf{x}, \mathbf{Y}, \mathbf{p}_{\mathbf{J}}, \mathbf{p}_{\mathbf{k}}, \mathbf{p}_{\mathbf{m} 1}, \mathbf{p}_{\mathbf{m}}, \lambda, \boldsymbol{\beta}, \mathbf{q}, \mathbf{q}, \mathbf{r}, \boldsymbol{\rho}, \mathbf{p}}{\operatorname{Max}} \phi=\sum_{j \in J} \sum_{m \in M} x_{j m} p_{m 2}\left(1-\hat{c}_{4} l_{j m}-\tilde{c}_{4}\right)-\sum_{j \in J} \sum_{m \in M} x_{j m}\left(p_{j}+c_{3} l_{j m}+c_{2}^{j}\right)-\sum_{j \in J} c_{1}^{j} Y_{j}
$$

$$
\text { s.t. (1)-(3), (5)-(6), (14)-(22). }
$$

In $\mathbf{P 2}$, the binary variables $\mathbf{Y}$ appear in both the quadratic objective function and complementarity constraints (22). Mak et al. (2013) observed that the incorporation of binary variables in non-linear constraints had significant impacts on solver's performance. The authors tested two sets of similar sized mixed-integer second-order conic problem instances (MISOCP): one set only involves continuous variables in the non-linear constraints, the other set involves binary variables in some of the non-linear 
constraints. The computation times for the first set varied from 2 minutes to 1.3 hours, while those in the second set required a much longer time from 2 hours to 4 days. Although P2 is solvable, there is a pressing need to decouple the integer variables from the complementarity constraints. We next develop a customized Lagrangian relaxation (LR) heuristic algorithm to do this.

\subsubsection{Lagrangian Relaxation Based Algorithm}

We first introduce a set of continuous variables $\mathbf{y}=\left\{y_{i}, i \in I\right\}$ to replace the binary variables $\mathbf{Y}=\left\{Y_{i}, i \in I\right\}$ in (22), such that all the complementarity constraints are relaxed to only involve continuous variables. Constraints (22) are replaced by (24)-(26).

$$
\begin{aligned}
& y_{j} \leq Y_{j} \quad \forall j \in J \quad \leftarrow \eta_{j} \\
& 0 \leq y_{j} \leq 1 \quad \forall j \in J \\
& 0 \leq \rho_{k} \perp S_{j} y_{j}-\sum_{i \in I} x_{i j} \geq 0 \quad \forall k \in K
\end{aligned}
$$

In order to decouple the binary location decisions $Y_{j}$ with the variables $x_{i j}$, we move constraints (24) to the objective function as penalty terms with Lagrangian multipliers $\boldsymbol{\eta}=\left\{\eta_{j}, j \in J\right\}$. The further relaxed problem is shown below as $\mathbf{P 3}$ :

(P3)

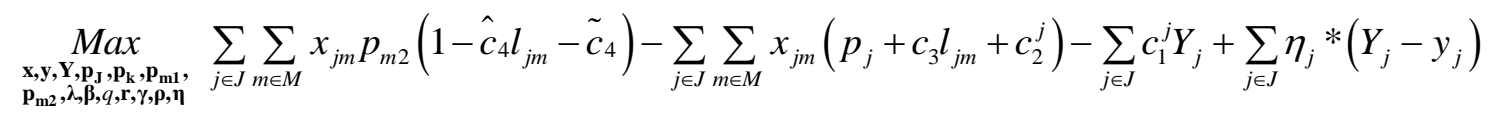

$$
\text { s.t. (1)-(3), (5)-(6), (14)-(21), (25)-(26) }
$$

Note that $\mathbf{P 3}$ can be decomposed into two sub problems:

(P3-1) facility location problem

$$
\underset{\mathbf{Y}}{\operatorname{Max}} \omega_{1}=\sum_{j \in J}\left(\eta_{j}-c_{1}^{j}\right) * Y_{j}
$$

$$
\text { s.t. (5) }
$$

(P3-2) grain assignment problem

$$
\underset{\mathbf{x}, \mathbf{y}, \mathbf{p}_{J}, \mathbf{p}_{\mathbf{k}}, \mathbf{p}_{\mathbf{m}}, \mathbf{p}_{\mathbf{m}}, \lambda, \mathbf{\beta}, q, \mathbf{r}, \gamma, \mathbf{p}}{\operatorname{Max}} \omega_{2}=\sum_{j \in J} \sum_{m \in M} x_{j m} p_{m 2}\left(1-\hat{c}_{4} l_{j m}-\tilde{c}_{4}\right)-\sum_{j \in J} \sum_{m \in M} x_{j m}\left(p_{j}+c_{3} l_{j m}+c_{2}^{j}\right)-\sum_{j \in J} \eta_{j} * y_{j}
$$

$$
\text { s.t. (1)-(3), (6), (14)-(21), (25)-(26). }
$$

P3-1 can be solved readily as follows: given the Lagrangian multipliers, set $Y_{j}=1$ if $\eta_{j} \geq c_{1}^{j}$ or 0 otherwise for every $j \in J$. P3-2 is an MPEC with only continuous variables, which can be solved by Knitro.

For any given value $\eta_{j}, \eta_{j} \geq 0$, it is easy to see that the optimal solution to $\mathbf{P 3}$ is an upper bound to that of the original problem $\mathbf{P 2}$ (due to consecutive relaxations). However, the solutions to the relaxed sub 
problems are often not feasible to $\mathbf{P 2}$. A feasible solution can be constructed based on the optimal facility location $\left\{Y_{j}, j \in J\right\}$ from P3-1; i.e., after fixing $Y_{j}, \forall j \in J, \mathbf{P 2}$ becomes a grain assignment problem that can be solved effectively. The resultant objective value shall be feasible and thus provides a lower bound.

The rest of the LR based algorithm, such as multiplier update, follows the standard approach (e.g., Fisher, 1981). The main steps are summarized as follows, where subscript $n$ denotes the iteration number. Control parameter $v$ is set to be 1 , the step size $\pi_{n}$ is reduced by half when $\pi_{n}>c_{1}^{j}$. The solution procedure terminates when the gap between the lower bound and the upper bound is less than a predetermined tolerance level $\varepsilon$, or if a pre-determined limit on the iteration number is reached.

Step 1: Initialization. Set iteration number $n=1, \eta_{j, n}=c_{1}^{j}$ for every $j \in J$. Let the lower bound $\phi_{L B}$ of the objective function of $\mathbf{P 2}$ be zero, and let the upper bound $\phi_{U B}$ be infinity.

Step 2: Based on the fixed $\left\{\eta_{j, n}, j \in J\right\}$, solve sub-problem P3-1 to get the optimal facility locations $\left\{Y_{j, n}, j \in J\right\}$ and the objective value $\omega_{1, \mathrm{n}}$. Solve P3-2 to obtain $\left\{y_{j, n}, j \in J\right\}$ and $\omega_{2, n}$.

Step 3. Calculate the new upper bound of $\mathbf{P 2}: \phi_{U B, \mathrm{n}}=\omega_{1, n}+\omega_{2, n}$. If $\phi_{U B, \mathrm{n}}<\phi_{U B}$, update the optimal upper bound $\phi_{U B}=\phi_{U B, \mathrm{n}}$.

Step 4. Fix the facility location $Y_{j}=Y_{j, n}, \forall j \in J$ in $\mathbf{P 2}$, solve it to obtain the lower bound $\phi_{L B, \mathrm{n}}$. If $\phi_{L B, \mathrm{n}}>\phi_{L B}$, update the optimal lower bound $\phi_{L B}=\phi_{L B, \mathrm{n}}$.

Step 5. Update $\eta_{j, n} \cdot \eta_{j, n+1}=\max \left\{0, \eta_{j, n}-\pi_{n}\left(Y_{j, n}-y_{j, n}\right)\right\}, \forall j \in J$, where the step size is chosen the same way as in Bai et al. (2011): $\pi_{n}=\frac{v\left[\phi_{U B, \mathrm{n}}-\phi_{L B, \mathrm{n}}\right]}{\sum_{j \in J}\left(Y_{j, n}-y_{j, n}\right)^{2}}$. Set $\pi_{n}=\frac{1}{2} \pi_{n}$ if $\pi_{n}>c_{1}^{j}$.

Step 6. Check if $\frac{\phi_{U B}-\phi_{L B}}{\phi_{U B}} \leq \varepsilon$ or if $n$ reaches the limit, stop. Otherwise, set $n=n+1$ and go to Step 2 .

\subsection{Risk-seeking Food Company}

State-owned companies can sometimes be more risk-seeking. They are concerned with not only their own profit but also some social responsibility (e.g., providing sufficient storage space). The risk-seeking food company determines the facility locations $\mathbf{Y}$ and grain purchase prices $\mathbf{p}_{\mathbf{J}}$ based on a bumper year scenario from the chosen uncertainty set. The upper level problem remains the same as P1-1, and the riskseeking food company faces a max-max problem. This allows us to add the constraints in the uncertainty set $U$ directly into the lower-level model formulation; i.e., (8) is replaced by (30)-(31), where $d_{i}$ represents the crop yield realization at farmer $i$ in the best scenario,

$$
\sum_{k \in K} x_{i k}+\sum_{m \in M} x_{i m}+\sum_{j \in J} x_{i j} \leq d_{i},
$$

$$
\overline{d_{i}}-d_{i} \leq d_{i} \leq \bar{d}_{i}+d_{i} \quad \forall i \in I ; \quad \sum_{i \in I} \frac{\left|d_{i}-\overline{d_{i}}\right|}{d_{i}} \leq \Gamma .
$$


1 To remove the absolute value operator, we introduce variables $z_{i}=\frac{\left|d_{i}-\overline{d_{i}}\right|}{d_{i}}, \forall i \in I$. The modified 2 lower level problem is written as follows:

3

21

22

23

24

25

26

27

28

29

30

31

(P4-2) for each farmer $i \in I$ :

$\operatorname{Max}(7)$

s.t. (1), (2), (9), (10), and

$$
\sum_{k \in K} x_{i k}+\sum_{m \in M} x_{i m}+\sum_{j \in J} x_{i j} \leq d_{i} \leftarrow \xi_{i}
$$

$$
z_{i} \geq 0
$$

Constraint (32) ensures the amount of grains sold by farmer $i$ cannot exceed the crop yield $d_{i}$. Constraints (33)-(38) linearize constraints (31). The Lagrangian multipliers $\xi_{i}, \chi_{i}^{1}, \chi_{i}^{2}, \chi_{i}^{3}, \chi_{i}^{4}, \kappa$ are shown alongside their associated constraints. Similarly, P4-2 can be replaced by its equivalent KKT conditions (21)-(22) and (40)-(50). The single level DC-MPEC for the risk-seeking company now becomes:

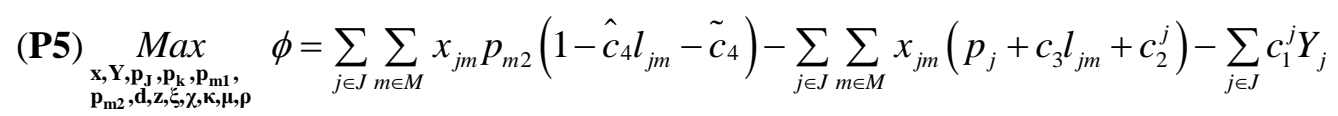

$$
\text { s.t. (1)-(3), (5)-(6), (21)-(22) and }
$$

$$
0 \leq x_{i k} \perp-p_{k}\left(1-c_{4} l_{i k}\right)+c_{3} l_{i k}-a_{k}\left(1-c_{4} l_{i k}\right) x_{i k}+\xi_{i}+\mu_{k} \geq 0 \quad \forall i \in I, k \in K
$$

$$
0 \leq x_{i j} \perp-p_{j}\left(1-c_{4} l_{i j}\right)+c_{3} l_{i j}+\xi_{i}+\rho_{j} \geq 0 \quad \forall i \in I, j \in J
$$

$$
0 \leq x_{i m} \perp-p_{m 1}\left(1-c_{4} l_{i m}\right)+c_{3} l_{i m}+c_{0}^{m}-a_{m 1}\left(1-c_{4} l_{i m}\right) x_{i m}+\frac{\partial c_{0}^{m}}{\partial x_{i m}} x_{i m}+\xi_{i} \geq 0, \forall i \in I, m \in M
$$

$$
0 \leq d_{i} \perp-\xi_{i}+\chi_{i}^{1}-\chi_{i}^{2}+\chi_{i}^{3}-\chi_{i}^{4} \geq 0 \quad \forall i \in I
$$

$$
0 \leq z_{i} \perp-\chi_{i}^{3}-\chi_{i}^{4}+\kappa \geq 0 \quad \forall i \in I
$$

$$
0 \leq \xi_{i} \perp d_{i}-\sum_{k \in K} x_{i k}-\sum_{m \in M} x_{i m}-\sum_{j \in J} x_{i j} \geq 0 \quad \forall i \in I
$$

$$
0 \leq \chi_{i}^{1} \perp \bar{d}_{i}+d_{i}-d_{i} \geq 0 \quad \forall i \in I
$$

$$
0 \leq \chi_{i}^{2} \perp d_{i}-\bar{d}_{i}-d_{i} \geq 0 \quad \forall i \in I
$$

$$
0 \leq \chi_{i}^{3} \perp \bar{d}_{i}+z_{i} d_{i}-d_{i} \geq 0 \quad \forall i \in I
$$




$$
\begin{aligned}
& 0 \leq \chi_{i}^{4} \perp-\bar{d}_{i}+z_{i} d_{i}+d_{i} \geq 0 \quad \forall i \in I \\
& 0 \leq \kappa \perp \Gamma-\sum_{i \in I} z_{i} \geq 0
\end{aligned}
$$

P5 resembles $\mathbf{P 2}$ in mathematical formulation except for some different complementarity constraints. The binary variables $\mathbf{Y}$ appear in the quadratic objective function (39) and complementarity constraints (22). The same LR-based algorithm as the one in Section 3.2 can be applied to P5 accordingly.

\section{CASE STUDY}

To demonstrate the applicability of the proposed models and algorithms, we apply them respectively to the corn logistics network of Illinois, U.S., and the soybean logistics network of Brazil. The proposed LRbased algorithm was programmed in AMPL and the reformulated DC-MPEC was solved by Knitro 9.1.0 on a 64-bit Intel i7-3770 computer with $3.40 \mathrm{GHz}$ CPU and 8G RAM, and only one thread was used.

\subsection{Illinois Case Study}

Illinois is one of the leading states for corn production and exportation in the U.S. We use the 2008 corn production data of the 102 counties in Illinois from Bai et al. (2012). The centroid of each county represents an individual farmer and a candidate processing/storage facility location. We assume that there are four export ports located at Chicago, St. Louis, Peoria, and Davenport (Nourbakhsh et al., 2015), and $|K|=14$ spatially distributed existing elevators each with a storage capacity of $S_{k}=20$ million bushels (mbu.). The centroids of $|J|=40$ counties are set as candidate PSF locations based on the accessibility to the ports and major highways (Bai et al., 2012). Each candidate PSF can store $S_{j}=50 \mathrm{mbu}$. of grains. The Chicago port is able to load corns onto ships at a rate of $s=6 \mathrm{mbu}$. /day and the other ports operate at a rate of $s=3 \mathrm{mbu}$. /day. The unit waiting cost at ports is $\alpha=0.081 \$ /$ bushel*day, consisting of PHL $0.003 \$ /$ bushel*day and truck holding cost (transportation cost) $0.078 \$ /$ bushel*day. The early harvest penalty is $\beta=0.025 \$ /$ bushel*day, and the late harvest penalty $\gamma=0.025 \$ /$ bushel*day. Hence the port congestion cost $c_{0}^{m}$ has two components: PHL caused by early/late harvest and waiting at the port, and the additional transportation cost caused by the excessive waiting time. The harvest ending time has a deadline that satisfies $\bar{t}-t^{*}=30$ days. From Proposition 1, we can get $c_{0}^{m}=0.0125 \frac{\sum_{i \in I} x_{i m}}{s}$ if the anticipated harvest ending time does not exceed the boundary $\bar{t}$, or $c_{0}^{m}=0.019 \frac{\sum_{i \in I} x_{i m}}{s}-0.396$ otherwise.

The fixed cost after depreciation and proration for PSF construction is $c_{1}^{j}=10$ million \$/year assuming a 25-year design life. The variable cost for corn processing is $c_{2}^{j}=0.16 \$ /$ bushel, which consists of labor, handling, and electricity costs. The unit transportation costs during the harvest and non-harvest seasons are $c_{3}=1.24 e^{-3} \$ / \mathrm{km} *$ bushel, and $\hat{c}_{3}=0.93 e^{-3}$ respectively. The PHL rates for the unprocessed and processed corns are set to be $c_{4}=6.8 e^{-6} \% / \mathrm{km}$ and $\hat{c}_{4}=4.0 e^{-6} \% / \mathrm{km}$, respectively. The PHL during processing is $\tilde{c}_{4}=1 \%$ at all PSFs. The corn production cost is $c_{5}=1.9 \$ / \mathrm{bushel}$. The unit price of corn 
1 before processing is $4.05 \$ /$ bushel, and $4.775 \$ /$ bushel after processing. The demand inverse functions are

2 assumed to be: $p_{k}=4.05-0.01 * \sum_{i \in I} x_{i k}, p_{m 1}=4.05-0.001 * \sum_{i \in I} x_{i m}$, and $p_{m 2}=4.775-0.001 * \sum_{j \in J} x_{j m}$.

3 Table 1 presents the computational results for risk-averse/-seeking companies, different uncertainty 4 sets and various cases with 30 -70 farmers. The first column shows the problem size; e.g., the centroids of

5 the $|I|$ top corn producing counties are selected to represent farmers, while the number of candidate PSFs,

6 existing elevators and markets remain the same. Recall that the uncertainty set gives the robust level,

$7 d_{i} / \overline{d_{i}}$, the variation range of each stochastic crop yield $D_{i}$, and the total deviation budget $\Gamma$. We allow

8 at most $30 \%$ of the farmers to reach their maximum crop yield deviation (i.e. $\Gamma=30 \% *|I|$ ). When $d_{i} / \overline{d_{i}}$

$9=0, \Gamma$ is also zero automatically. A combination of company type and the size of the uncertainty set

$10\left(d_{i} / \overline{d_{i}}\right.$ and $\left.\Gamma\right)$ can be regarded as a strategy of the food company to handle the risks associated with

11 yield uncertainties. For example, the strategy with risk-averse company and a robust level of 0.3 deals

12 with the worst harvest year among the five cases with the lowest crop yield. While the strategy with risk-

13 seeking company and a robust level of 0.3 deals with the best harvest year scenario with the highest crop 14 yield.

15

Table 1. Computation results for the Illinois case study

\begin{tabular}{|c|c|c|c|c|c|c|c|c|c|c|}
\hline \multirow{2}{*}{$\begin{array}{l}\text { Problem size a }^{\text {Prom }} \\
(|I|,|J|,|K|,|M|)\end{array}$} & \multirow{2}{*}{$\begin{array}{l}\text { Company } \\
\text { type }^{\mathrm{b}}\end{array}$} & \multicolumn{2}{|c|}{$\begin{array}{c}\text { Uncertainty } \\
\text { set }\end{array}$} & \multirow{2}{*}{$\begin{array}{l}\text { Total } \\
\text { crop } \\
\text { yield } \\
\text { (mbu.) }\end{array}$} & \multirow{2}{*}{$\begin{array}{l}\text { No. } \\
\text { of } \\
\text { PSF }\end{array}$} & \multirow{2}{*}{ ROI } & \multirow{2}{*}{$\begin{array}{l}\text { Company's } \\
\text { annual } \\
\text { profit } \\
\text { (million \$) } \\
\end{array}$} & \multirow{2}{*}{$\begin{array}{c}\text { Farmer's } \\
\text { annual } \\
\text { profit } \\
\text { (million \$) }\end{array}$} & \multirow{2}{*}{$\begin{array}{c}\text { CPU } \\
\text { time } \\
\text { (s) }\end{array}$} & \multirow{2}{*}{$\begin{array}{l}\text { Resi- } \\
\text { dual } \\
\text { Gap } \\
(\%)\end{array}$} \\
\hline & & $d_{i} / \overline{d_{i}}$ & $\Gamma$ & & & & & & & \\
\hline \multirow{5}{*}{$\begin{array}{c}(30,40,14,4) \\
5600 \text { variables, } \\
1800 \text { C.C. and } \\
3700 \text { L.C. }\end{array}$} & Risk A. & 0.30 & 9 & 1002 & 9 & 2.26 & 203 & 759 & 820 & 0 \\
\hline & Risk A. & 0.15 & 9 & 1071 & 11 & 2.79 & 306 & 1353 & 1000 & 3.7 \\
\hline & De. & 0 & 0 & 1140 & 11 & 3.86 & 425 & 1809 & 701 & 2.7 \\
\hline & Risk S. & 0.15 & 9 & 1210 & 12 & 3.87 & 464 & 2005 & 1280 & 0.2 \\
\hline & Risk S. & 0.30 & 9 & 1279 & 12 & 4.35 & 521 & 2141 & 1311 & 0 \\
\hline \multirow{5}{*}{$\begin{array}{c}(50,40,14,4) \\
9100 \text { variables, } \\
3000 \text { C.C., and } \\
5900 \text { L.C. }\end{array}$} & Risk A. & 0.30 & 15 & 1469 & 12 & 3.05 & 366 & 851 & 2416 & 4.4 \\
\hline & Risk A. & 0.15 & 15 & 1578 & 12 & 4.59 & 550 & 1393 & 3096 & 2.4 \\
\hline & De. & 0 & 0 & 1687 & 14 & 5.04 & 761 & 1948 & 3919 & 2.5 \\
\hline & Risk S. & 0.15 & 15 & 1795 & 16 & 5.41 & 865 & 2166 & 4405 & 0 \\
\hline & Risk S. & 0.30 & 15 & 1904 & 17 & 5.75 & 978 & 2370 & 4067 & 0 \\
\hline \multirow{5}{*}{$\begin{array}{c}(70,40,14,4) \\
12600 \text { variables, } \\
4200 \text { C.C., and } \\
8200 \text { L.C. }\end{array}$} & Risk A. & 0.30 & 21 & 1685 & 13 & 3.81 & 494 & 877 & 2134 & 3.3 \\
\hline & Risk A. & 0.15 & 21 & 1790 & 14 & 5.38 & 753 & 1471 & 4312 & 0 \\
\hline & De. & 0 & 0 & 1966 & 17 & 6.21 & 1055 & 2021 & 4000 & 0.8 \\
\hline & Risk S. & 0.15 & 21 & 2106 & 18 & 6.67 & 1199 & 2207 & 13263 & 0.6 \\
\hline & Risk S. & 0.30 & 21 & 2247 & 19 & 7.09 & 1347 & 2380 & 5979 & 0.8 \\
\hline
\end{tabular}

${ }^{\mathrm{a}}$ C.C. $=$ complementarity constraints; L.C. $=$ linear constraints

${ }^{\mathrm{b}}$ Risk A. = risk averse; Risk S. = risk seeking; De. = Deterministic

As shown in Table 1, the average computation times for the cases with 30, 50, and 70 farmers are 1022s, 3580s, and 5937s respectively. We can see that most cases can be solved in a reasonable time to a reported residual gap of less than 5\%. It shall however be noted that due to non-convexity of the problem, 
global optimality cannot be guaranteed even if the gap is $0 \%$. This shortcoming can be partially mitigated by trying multiple starting points, albeit incurring a longer computation time.

In general, the number of built PSFs in the model solution grows when the company changes from risk averse to risk seeking. This makes sense. Intuitively, having more PSFs provides the capability of better hedging again crop yield uncertainties, but the downside is that when the realized crop yield is low, these PSFs will be under-utilized. Hence, the risk-averse company tends to build fewer PSFs to ensure profitability even under the worst crop yield. The optimistic risk-seeking company, on the other hand, is willing to build more PSFs to maximize its potential profit. For each problem size, the company's "planned" total crop yield in the worst-/best-case scenario $\left(\sum_{k \in K} x_{i k}+\sum_{m \in M} x_{i m}+\sum_{j \in J} x_{i j}\right.$ in $\mathbf{P 2}$ or P5) under each strategy gradually increases from the top row to the bottom row. If we use the return on investment (ROI; i.e., the annual profit divided by the cost of PSF construction) as a performance measure, we can observe that ROI increases with the planned total crop yield, and so do the annual profits of the company and the farmers.

However, the actual crop yield may not follow the selected worst/best scenario, and it is wellknown that the solution from a robust optimization model tends to be overly conservative (or aggressive in the risk seeking case). For example, the risk-averse company could fail to gain more profits due to insufficient storage and high prices, even when a good harvest year comes. Hence, while evaluating the model solution with randomly generated crop yield scenarios, we do not hold the values of all decisions, i.e., $\mathbf{Y}, \mathbf{P}_{\mathrm{J}}$ and correspondingly $\mathbf{X}_{\mathrm{IJ}}, \mathbf{X}_{\mathrm{IK}}, \mathbf{X}_{\mathrm{IM}}, \mathbf{X}_{\mathrm{JM}}$, as fixed; instead, we believe it is more realistic to fix only $\mathbf{Y}$ (sometimes referred to as control variables) and allow $\mathbf{P}_{\mathrm{J}}, \mathbf{X}_{\mathrm{IJ}}, \mathbf{X}_{\mathrm{IK}}, \mathbf{X}_{\mathrm{IM}}, \mathbf{X}_{\mathrm{JM}}$ (sometimes referred to as state variables) to vary with crop yield realizations. Similar evaluation approaches have been seen in Ben-Tal et al. (2011). To this end, for each crop yield realization, P1 is applied after the following modifications: (i) the stochastic demand $D_{i}$ in constraint (8) is replaced by its realization; (ii) we fix $\mathbf{Y}$ but keep $\mathbf{P}_{\mathrm{J}}$ and $\mathbf{X}_{\mathrm{IJ}}, \mathbf{X}_{\mathrm{IK}}, \mathbf{X}_{\mathrm{IM}}, \mathbf{X}_{\mathrm{JM}}$ as decision variables. This modified $\mathbf{P 1}$ becomes a deterministic bilevel problem with only continuous variables. It can be further relaxed into a single-level problem by using the KKT conditions, which becomes readily solvable (e.g., by the Knitro solver). Doing the above for all the generated scenarios, we can evaluate the company's profit expectation and other performance statistics.

We use Latin Hypercube Sampling (Lo et al., 2013) to generate 100 samples of crop yield realizations, assuming normally distributed stochastic crop yields whose means follow the county-level corn production in Illinois in 2008, and variances equal to the corresponding means (Bai et al., 2012). We then select the optimal PSF location design under each of the 50-farmer cases (the third row in Table 1), and evaluate its performance under these crop yield realizations. Fig. 2 plots the maximum, minimum and average (plus or minus 3 standard deviations) of the company's and farmers' total profits. It can be seen from Fig. 2a that the company's strategy does not have a substantial impact on its average profit. The company's minimum profit drops when the company changes from risk-averse to risk-seeking while its maximum profit rises, leading to increasing profit variations. This result demonstrates that a risk-seeking company does get exposed to higher risks while facing profit uncertainties. Fig. $2 b$ presents the impacts of the company's strategy on farmers' profits. The farmers' average profit increases significantly when the company adopts risk seeking strategy. However, the increase in farmers' minimum profit is rather small, indicating that the farmers could not benefit much from storage increases when the yield realization is low. 


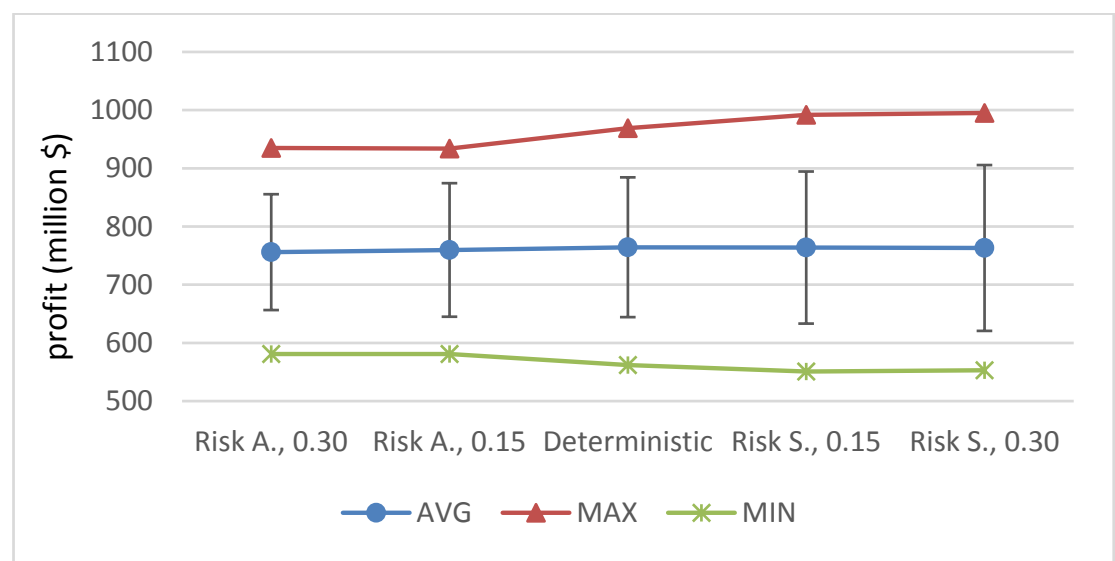

(a) The company's profit (million \$)

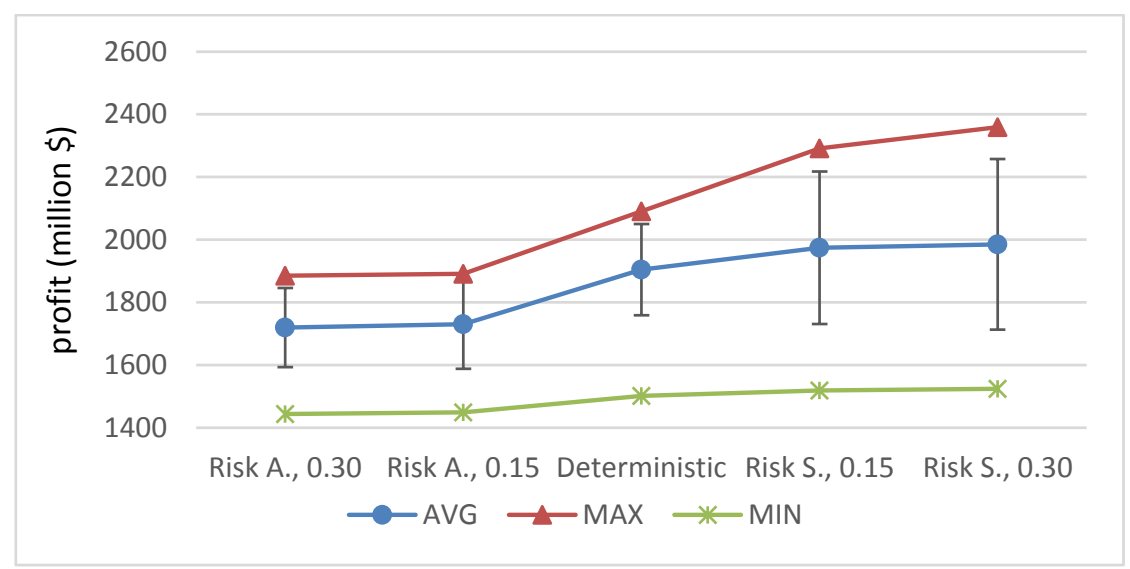

(b) The farmers' profit (million \$)

Fig. 2 The realized profits for the cases with 50 farmers

To evaluate the actual performance of different strategies, Table 2 presents average performance measures across the 100 samples. The risk-seeking strategy does not impair the company's average profit significantly, but it could benefit the farmers remarkably, owing to the reduction in PHL (due to more PSFs). The facility usage declines from 1 to 0.88 as the number of PSFs increases, indicating a certain level of over-investment. The return of investment also drops substantially. Given a similar net profit, low investment always leads to high ROI. This explains why a private company often adopts risk-averse strategies. The PHL and transportation cost paid by the company fluctuate with small variations. From the perspective of the farmers, more PSFs always bring them higher profit, lower PHL, and lower transportation cost. Sufficient storage capacity attracts more corns to PSFs thus can mitigate the port congestion, which decreases the PHL and transportation cost caused by the excessive waiting time at the ports. It also enables the farmers to harvest near the preferred harvest time and further brings down the PHL. Total PHL of the company and the farmers constitutes $6.9 \%$ of their total revenue (profit + cost) when the number of PSFs is 12 in the first row, and this value drops to $4.1 \%$ when the number of PSFs reaches 17 . The total transportation cost drops from $10.9 \%$ of their total revenue to $7.3 \%$. Indeed, the 
storage capacity has a significant impact on the societal dis-benefits (PHL and transportation cost). Enhancing the storage capacity is not only appealing to the farmers but also beneficial to the government.

Table 2. Averaged performance measures for the cases with 50 farmers

\begin{tabular}{|c|c|c|c|c|c|c|c|c|c|c|}
\hline \multirow{2}{*}{ Strategy } & \multirow{2}{*}{$\begin{array}{l}\text { No.of } \\
\text { PSF }\end{array}$} & \multirow{2}{*}{ ROI } & \multirow{2}{*}{$\begin{array}{l}\text { PSF } \\
\text { usage }\end{array}$} & \multicolumn{2}{|c|}{ Profit (million \$) } & \multicolumn{2}{|c|}{ PHL(million \$) } & \multicolumn{2}{|c|}{$\begin{array}{l}\text { Transportation } \\
\text { cost (million \$) }\end{array}$} & \multirow{2}{*}{$\begin{array}{c}\text { Subsidy } \\
\text { (million \$) }\end{array}$} \\
\hline & & & & Comp. & Farmer & Comp. & Farmer & Comp. & Farmer & \\
\hline (Risk A., 0.30) & 12 & 6.3 & 1.00 & 756 & 1720 & 29 & 372 & 58 & 577 & 0 \\
\hline (Risk A., 0.15) & 12 & 6.3 & 1.00 & 759 & 1731 & 29 & 367 & 70 & 568 & 0 \\
\hline (Risk A./S., 0) & 14 & 5.5 & 0.99 & 764 & 1905 & 33 & 296 & 66 & 504 & 19 \\
\hline (Risk S., 0.15) & 16 & 4.8 & 0.92 & 763 & 1975 & 35 & 267 & 75 & 462 & 39 \\
\hline (Risk S., 0.30) & 17 & 4.5 & 0.88 & 763 & 1985 & 36 & 261 & 73 & 451 & 49 \\
\hline
\end{tabular}

4

Risk seeking strategy of the food company harms the ROI of the company but favors the farmers in every aspect. From the perspective of the government, it is worthwhile to establish a subsidy scheme to equitably balance the loss of the company and the gain of the farmers. One potential way is to provide low interest loan to the company to ease its investment pressure. To maintain the highest ROI of 6.3, the food company would at most invest about $15 \%$ of its profit (i.e., 1/6.3) in building PSFs. The difference of the wished investment and the actual investment in PSF construction provides a guideline for the government's subsidy, which is shown in the last column. Suppose the government provides a zerointerest loan of the value in the last column, the food company is able to maintain the same ROI by adopting any strategy. We may be able to establish a more elaborated subsidy scheme with proper interest rate and check if a win-win-win situation among the company, farmers and the government can be achieved. This is left for the future study.

\subsection{Brazil Case Study}

In this case study, 33 major Brazilian agricultural regions are selected to represent farmers as well as candidate PSF locations. These regions contribute to 83\% of Brazil's total soybean production in 2013 (Salin, 2014). We consider the 9 largest Brazilian ports, as indicated by the solid circles in Fig. 3, which collectively handle $90 \%$ of total soybean exports (Robert and Caleb, 2014b). We choose 18 existing elevators to be respectively located at the centers of the 18 states with the highest storage capacity. The loading rates at ports, storage capacity in the existing elevators, soybean production cost, soybean prices before and after processing, unit transportation costs during harvest and non-harvest seasons follow the data from the United States Department of Agriculture/Foreign Agricultural Services (USDA/FAS) (Salin, 2014; 2015; Robert and Caleb, 2014a; 2014b). Based on soybean production records in the recent 10 years, we set the maximum deviation of the stochastic soybean production $d_{i} / \bar{d}_{i}=19 \%$, and total deviation budget $\Gamma=7$. In PSF performance evaluation, the stochastic crop yield in an arbitrary region $i$ is normally distributed with the mean equal to the regional soybean production $\bar{d}_{i}$ in 2013 , and the standard deviation equal to $0.13 * \bar{d}_{i}$. All other parameters are set to be the same as those in the Illinois case study. 


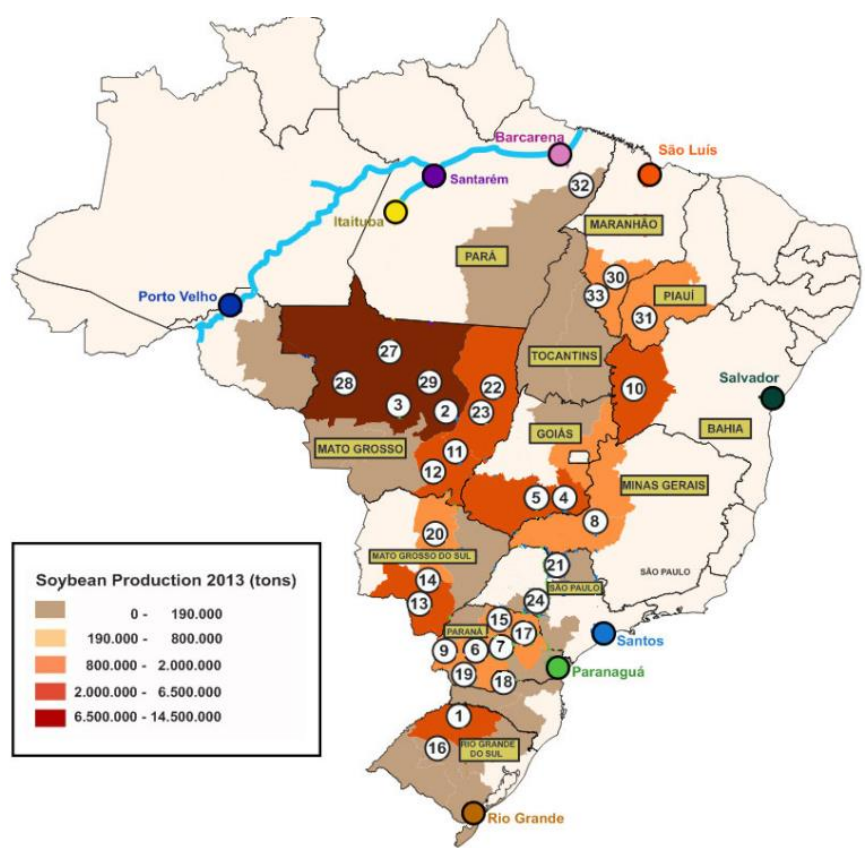

Fig. 3 Main soybean production and export locations in Brazil (Source: Salin, 2015)

The proposed models and solution algorithms are applied. The risk-seeking company builds 15 PSFs while the risk-averse company builds 11 PSFs as shown in Fig. 4. For both types of companies, more than $40 \%$ of these PSFs are clustered in the southern part of the country due to good accessibility to the three major ports: Santos, Paranaguá, and Rio Grande. These ports export around $70 \%$ of annual soybean productions (Robert and Caleb, 2014b). In the rest of the country, the PSFs are somewhat evenly distributed. Although 6 ports are located in the northern part of the country, they are not able to attract as much soybean exports as one would expect -- three of these ports are not even used at all by the riskaverse company. In the future, it might be appealing if the Brazilian government could improve the transportation infrastructures (railroad, highway) between the central regions and the northern ports. This will increase the patronage to the northern ports, mitigate the congestion at the southern ports, and significantly decrease the overall PHL in the system. 


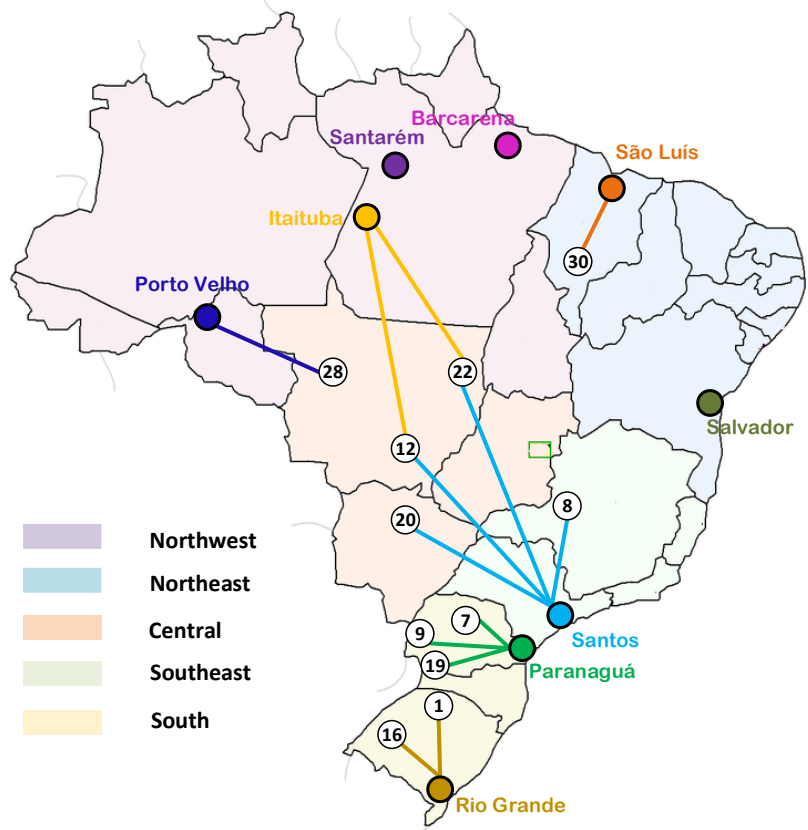

(a)

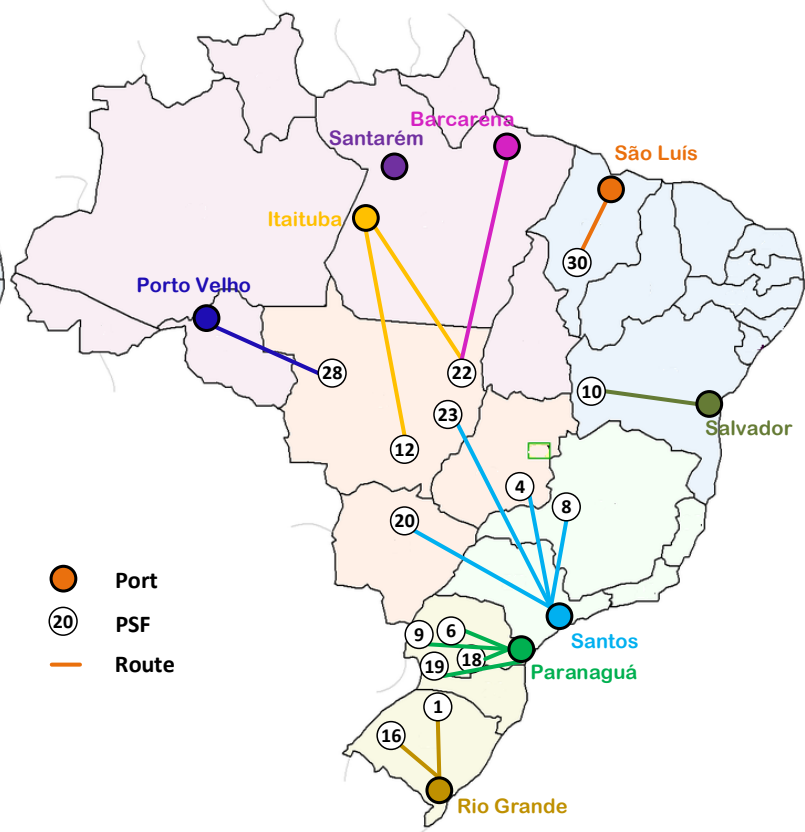

(b)

Fig. 4. Optimal PSF locations for (a) a risk-averse company, and (b) a risk-seeking company.

The average performance measures are presented in Table 3. Overall, the risk-seeking company earns $9.6 \%$ more profit than the risk-averse company by investing $36 \%$ more in building PSFs. Consequently, the ROI drops by $20 \%$. The government, if needed, could provide zero-interest loan of $\$ 30.7$ million to the risk-seeking company to offset its losses in ROI. Farmers' profit is increased by $\$ 146$ million if 15 PSFs are built. Moreover, with the risk-seeking company, the system-wide total PHL and the transportation cost are $6.8 \%$ and $2.8 \%$ lower, respectively. Currently, the total soybean production in Brazil is increasing dramatically at a rate of around $10 \%$ per year (Salin, 2014). This brings both opportunities and challenges. In light of this situation, a risk-seeking strategy together with a proper government subsidy scheme could maintain the company's profit while ensuring sufficient storage capacity, which in turn encourages more sustainable agriculture development in Brazil.

Table 3. Averaged performance measures for the Brazil case

\begin{tabular}{cccccccccccc}
\hline \multirow{2}{*}{ Strategy } & \multirow{2}{*}{$\begin{array}{c}\text { No. of } \\
\text { PSF }\end{array}$} & ROI & $\begin{array}{c}\text { PSF } \\
\text { usage }\end{array}$ & & \multicolumn{2}{c}{ Profit (million \$) } & PHL(million \$) & \multicolumn{2}{c}{$\begin{array}{c}\text { Transportation } \\
\text { cost (million \$) }\end{array}$} & \multirow{2}{*}{$\begin{array}{c}\text { Subsidy } \\
\text { (million }\end{array}$} \\
\cline { 7 - 10 } & & & & & Comp. & Farmer & Comp. & Farmer & Comp. & Farmer & \$) \\
\hline Risk A. & 11 & 4.6 & 1.00 & 501 & 6611 & 68 & 343 & 468 & 1319 & 0 \\
Risk S. & 15 & 3.7 & 0.95 & 549 & 6757 & 86 & 297 & 570 & 1168 & 30.7 \\
\hline Comparison (\%) & 36 & -20 & -5 & 9.6 & 2.2 & -6.8 & -2.8 & N/A \\
\hline
\end{tabular}

\section{CONCLUSION}

This paper is the first endeavor to integrate market equilibrium among farmers, stochastic crop yields, and post-harvest loss, into the design of grain supply chain systems. We model a three-stage supply chain network, which consists of farmers, storage facilities and export markets. A bi-level leader-follower game 
1 is proposed to deal with decentralized decision-making and market equilibria. A robust program 2 formulation is used to deal with the crop yield uncertainty. Finally, a bottleneck model is used to study 3 harvest time equilibrium among multiple independent farmers, and the resulted PHL during harvest, 4 transportation, etc. These modeling efforts lead to a challenging robust bi-level problem, which is then 5 transformed into an equivalent single-level problem with complementarity constraints. A Lagrangian 6 relaxation algorithm is proposed to solve the proposed problem effectively, and the modeling framework 7 is applied to Illinois and Brazil case studies for managerial insights.

8 The proposed models allow the food company to adopt risk-seeking/risk-averse strategies to deal 9 with different uncertainty sets related to crop yields; the impacts of such choices on the system 10 performance are evaluated. Numerical results of the Illinois and Brazil case studies show interesting 11 insights. For example, the risk seeking strategies tend to favor more PSF construction, hence led to great 12 savings of system-wide post-harvest loss and transportation cost. However, the ROI of the food company 13 is lower under such aggressive strategies. The company, if more concerned with its own financial 14 viability, would tend to prefer risk-averse strategies, but the farmers would benefit more from the risk seeking strategies. In light of this, possible governmental subsidy schemes that balance the gains and losses among different parties may be suitable for future studies.

Future research can be conducted in several directions. Risk-neutral companies, who maximize the expected profit, could be considered and compared in future case studies. In this paper, we assumed a widely-used yet rather simple uncertainty set. Given the mean, variance and support information of the stochastic crop yield, one may further apply distributional robust optimization methods to calculate the expected profit under the supremum distribution over the qualified distribution family. In this paper, trucks are considered as the only transportation mode. Multiple transportation modes, such as trains and trucks, or even intermodal transportation, may have a significant impact on the optimal facility location and port congestion. Transportation time between county centroids is assumed to be proportional to the distance. Nevertheless, highways could get congested due to the heavy truck flows. It is worthwhile to study the impacts of traffic congestion on farmers' route choices, which can be addressed by replacing the linear travel time function in our model by their non-linear Bureau of Public Roads (BPR) counterparts (e.g., as in Bai et al., 2011). Finally, this paper considers a push supply chain where the food products are pushed through the logistic channel, from the production side (farmer) up to the retailer (export ports). The export ports are assumed to be the final markets and can absorb all productions from the farmers, while the customer demand in the final step is ignored. In future studies, we can consider a complete supply chain and respond the customer demand by incorporating demand functions. 


\section{References}

Ahmadi-Javid, A., Azad, N., 2010. Incorporating location, routing and inventory decisions in supply chain network design. Transportation Research Part E 46(5), 582-597.

Ahmadi-Javid, A., Seddighi, A.H., 2013. A location-routing problem with disruption risk. Transportation Research Part E 53, 63-82.

Ahumada, O., Villalobos, J.R., 2009. Application of planning models in the agri-food supply chain: A review. European Journal of Operational Research 196(1), 1-20.

Allen, S. J., Schuster, E. W., 2004. Controlling the risk for an agricultural harvest. Manufacturing \& Service Operations Management, 6(3), 225-236.

An, K., Lo, H.K., 2014a. Robust transit network design with stochastic demand. Transportation Research Record 2467, 101-109.

An, K., Lo, H.K., 2014b. Ferry service network design with stochastic demand under user equilibrium flows. Transportation Research Part B 66, 70-89.

An, K., Lo, H.K., 2015. Robust transit network design with stochastic demand considering development density. Transportation Research Part B. In press.

Apaiah, R. K., Hendrix, E. M., 2005. Design of a supply chain network for pea-based novel protein foods. Journal of Food Engineering, 70(3), 383-391.

Arnott, R., de Palma, A., Lindsey, R., 1991. A temporal and spatial equilibrium analysis of commuter parking. Journal of Public Economics 45(3), 301-335.

Baghalian, A., Rezapour, S., Farahani, R.Z., 2013. Robust supply chain network design with service level against disruptions and demand uncertainties: A real-life case. European Journal of Operational Research 227(1), 199-215.

Bai, Y., Hwang, T., Kang, S., Ouyang, Y., 2011. Biofuel refinery location and supply chain planning under traffic congestion. Transportation Research Part B 45(1), 162-175.

Bai, Y., Ouyang, Y., Pang, J., 2012. Biofuel supply chain design under competitive agricultural land use and feedstock market equilibrium. Energy Economics 34(5), 1623-1633.

Bai, Y., Ouyang, Y. and Pang, J.S., 2016. Enhanced models and improved solution for competitive biofuel supply chain design under land use constraints. European Journal of Operational Research, 249(1), 281-297.

Ben-Tal, A., Boyd, S., Nemirovski, A., 2006. Extending scope of robust optimization: comprehensive robust counterparts of uncertain problems. Mathematical Programming 107(1-2), 63-89.

Ben-Tal, A., Chung, B.D., Mandala, S.R., Yao, T., 2011. Robust optimization for emergency logistics planning: Risk mitigation in humanitarian relief supply chains. Transportation Research Part B 45(8), 1177-1189.

Bertsimas, D., Thiele, A., 2006. A Robust Optimization Approach to Inventory Theory. Operation Research 54(1), 150-168.

Blackburn, J., Scudder, G., 2009. Supply chain strategies for perishable products: the case of fresh produce. Production and Operations Management, 18(2), 129-137.

Borodin, V., Bourtembourg, J., Hnaien, F., Labadie, N., 2014. A quality risk management problem: case of annual crop harvest scheduling. International Journal of Production Research, 52(9), 2682-2695.

Cardona-Valdes, Y., Alvarez, A., Pacheco, J., 2014. Metaheuristic procedure for a bi-objective supply chain design problem with uncertainty. Transportation Research Part B 60, 66-84.

Cordonnier, M., 2014. Lack of Grain Storage Chronic Problem in Brazil. Retrieved from http://cornandsoybean.com/news/Oct3_14-Lack-of-Grain-Storage-Chronic-Problem-in-Brazil. Accessed on October 20, 2015.

Cordonnier, M., 2015. Brazil Month-By-Month Crop Cycle. Retrieved from http://www.soybeansandcorn.com/Brazil-Crop-Cycles. Accessed on October 20, 2015.

Cui, T., Ouyang, Y., Shen, Z.J.M., 2010. Reliable facility location design under the risk of disruptions. Operations Research 58, 998-1011. 
Daskin, M.S., 1995. Network and discrete location: Models, algorithms, and applications. John Wiley and Sons, New York.

International Maize and Wheat Improvement Center, 2012. Effective grain storage project. Retrieved from http://www.cimmyt.org/en/projects/effective-grain-storage-project/about-the-project. Accessed on October 20, 2015.

The Crop Site, 2014. EU Grain Storage 'Insufficient'. Retrieved from http://www.thecropsite.com/news/17153/eu-grain-storage-insufficient. Accessed on October 20, 2015.

Fisher, M.L., 1981. The Lagrangian relaxation method for solving integer programming problems. Management Science 27(1), 1-18.

Grolleaud, M., 2002. Post-harvest losses: Discovering the full story. Overview of the phenomenon of losses during the Post-harvest system. Agricultural Support Systems Division, Food and Agriculture Organisation, Rome .

Gustavsson, J., Cederberg, C., Sonesson, U., 2011. Global food losses and food waste. Food and Agriculture Organization of the United Nations, Rome.

Hajibabai, L., Bai, Y., Ouyang, Y., 2014. Joint optimization of freight facility location and pavement infrastructure rehabilitation under network traffic equilibrium. Transportation Research Part B: Methodological 63, 38-52.

Hajibabai, L., Ouyang, Y., 2013. Integrated planning of supply chain networks and multimodal transportation infrastructure expansion: Model development and application to the biofuel industry. Computer-Aided Civil and Infrastructure Engineering, 28(4), 247-259.

Higle, J.L., Sen, S., 1996. Stochastic Decomposition:A Statistical Method for Large Scale Stochastic Linear Programming, Kluwer, Dordrecht; Boston.

Li, X. and Ouyang, Y., 2010. A continuum approximation approach to reliable facility location design under correlated probabilistic disruptions. Transportation Research Part B, 44(4), 535-548.

Li, X., Ouyang,Y., Peng, F., 2013. A supporting station model for reliable infrastructure location design under interdependent disruptions. Transportation Research Part E: Logistics and Transportation Review 60, 80-93.

Lo, H.K., An, K., Lin, W., 2013. Ferry service network design under demand uncertainty. Transportation Research Part E: Logistics and Transportation Review 59, 48-70.

Mak, H., Rong, Y., Shen, Z.M., 2013. Infrastructure Planning for Electric Vehicles with Battery Swapping. Management Science 59(7), 1557-1575.

Meixell, M.J., Gargeya, V.B., 2005. Global supply chain design: A literature review and critique. Transportation Research Part E: Logistics and Transportation Review 41(6), 531-550.

Melo, M.T., Nickel, S., Saldanha-da-Gama, F., 2009. Facility location and supply chain management - A review. European Journal of Operational Research 196(2), 401-412.

Nourbakhsh, S.M., Bai, Y., Maia, GDN., Ouyang Y., Rodriguez, L., 2015. Grain Supply Chain Network Design and Logistics Planning for Reducing Post-Harvest Loss. Transportation Research Board 94th Annual Meeting.

Pack, D., Robinson, K., 2015. About $\$ 300$ million in Indiana crops' value lost to flooding so far. Retrieved from http://www.purdue.edu/newsroom/releases/2015/Q2/300-million-in-indiana-cropsvalue-lost-to-flooding-so-far.html. Accessed on October 20, 2015.

Park, S., Lee, T., Sung, C.S., 2010. A three-level supply chain network design model with risk-pooling and lead times. Transportation Research Part E: Logistics and Transportation Review 46(5), 563-581.

Robert, K. H., Caleb, O., 2014a. Brazil oilseeds and products annual. U.S. Dept. of Agriculture, Agricultural Marketing Service. Web. < http://www.fas.usda.gov/data/brazil-oilseeds-and-productsannual-0>. Accessed on June 17, 2015.

Robert, K. H., Caleb, O., 2014b. North and northeast Brazil port infrastructure report. U.S. Dept. of Agriculture, Agricultural Marketing Service. Web. < http://gain.fas.usda.gov/Recent\%20GAIN\% 20Publications/North\%20and\%20Northeast\%20Brazil\%20Port\%20Infrastructure\%20Report_Brasilia _Brazil_1-9-2014.pdf>. Accessed on June 17, 2015. 
Ramaswami B., 2013. Grain stocks: Is it a problem of storage capacity. Livemint. Retrieved from http://www.livemint.com/Opinion/ryjIsy6fBOHyGAtMKin1rO/Grain-stocks-Is-it-a-problem-ofstorage-capacity.html. Accessed on June 17, 2015.

Rubio, N., 2015. United States Department of Agriculture (USDA) report on Brazil oilseeds and products update. Retrieved from http://www.fas.usda.gov/data/brazil-oilseeds-and-products-update-4. Accessed on October 20, 2015.

Ruszczynski, A., 2008. Decomposition Methods. In: Anonymous Handbooks in Operations Research and Management Science, Elsevier, pp. 141-211.

Salin, D.L., 2014. Soybean Transportation Guide: Brazil. U.S. Dept. of Agriculture, Agricultural Marketing Service. Web. <http://dx.doi.org/10.9752/TS048.06-2014>.

Salin, D.L., 2015. Soybean Transportation Guide: Brazil. U.S. Dept. of Agriculture, Agricultural Marketing Service. Web: < http://www.ams.usda.gov/AMSv1.0/getfile?dDocName=STELPRDC511 1588>. Accessed on July 3, 2015.

Sharon, M., Abirami, C. V., Alagusundaram, K, 2014. Grain storage management in India. Journal of Post-Harvest Technology 2(1), 12-24.

Stewart, A., 2013. Brazil Crop Outlook-3: Has Brazil hit a logistics wall. DTN/The Progressive Farmer. Retrieved from http://www.dtnprogressivefarmer.com/dtnag/news. Accessed on June 17, 2015.

Tucker, E., 2015. Alberta declares disaster after losses from drought. Retrieved from http://globalnews.ca/news/2179582/alberta-declares-disaster-after-losses-from-drought. Accessed on October 20, 2015.

Vahdani, B., Tavakkoli-Moghaddam, R., Modarres, M., Baboli, A., 2012. Reliable design of a forward/reverse logistics network under uncertainty: A robust-M/M/c queuing model. Transportation Research Part E-Logistics and Transportation Review 48(6), 1152-1168.

Vickrey, W.S., 1969. Congestion theory and transport investment. The American Economic Review 59, 251-261.

Wang, X., Lim, M.K. and Ouyang, Y., 2015. Infrastructure deployment under uncertainties and competition: The biofuel industry case. Transportation Research Part B: Methodological 78, 1-15.

Wang, X., Ouyang, Y., Yang, H., Bai, Y., 2013. Optimal biofuel supply chain design under consumption mandates with renewable identification numbers. Transportation Research Part B 57, 158-171.

Xie, S., Li, X. and Ouyang, Y., 2015. Decomposition of general facility disruption correlations via augmentation of virtual supporting stations. Transportation Research Part B 80: 64-81.

Yang, H., Liu, W., Wang, X., Zhang, X., 2013. On the morning commute problem with bottleneck congestion and parking space constraints. Transportation Research Part B 58, 106-118.

Zorya, S., Morgan, N., Diaz Rios, L., Hodges, R., Bennett, B., Stathers, T., Mwebaze, P., Lamb, J., 2011. Missing food: the case of postharvest grain losses in sub-Saharan Africa. 


\section{Appendix A: List of Notation}

Parameters

\begin{tabular}{|c|c|}
\hline$I, J, K, M$ & Sets of farmers, processing/storage facilities (PSF), existing local elevators, and export ports \\
\hline$D_{i}$ & Stochastic crop yield at farmer $i$ (mbu.) \\
\hline $\bar{d}_{i}, d_{i}$ & Crop yield expectation and maximum deviation at farmer $i$ (mbu.) \\
\hline$d_{i}$ & Crop yield realization at farmer $i$ in the best scenario \\
\hline$U$ & Uncertainty set of the stochastic crop yields \\
\hline$\Gamma$ & Deviation budget \\
\hline$S_{k}, S_{j}$ & Storage capacities of elevator $k$ and PSF $j$ (mbu.) \\
\hline$s$ & Port loading speed (mbu./day) \\
\hline$p_{k}(\cdot)$ & Elastic grain price at elevator $k(\$ /$ bushel $)$ \\
\hline$p_{m 1}(\cdot), p_{m 2}(\cdot)$ & Elastic grain prices at export port $m$ before and after processing $(\$ / b u s h e l)$ \\
\hline $\begin{array}{l}b_{k}, a_{k}, b_{m 1} \\
a_{m 1}, b_{m 2}, a_{m 2}\end{array}$ & Constant parameters in grain price functions \\
\hline$c_{1}^{j}$ & Construction cost of a PSF at $j(\$)$ \\
\hline$c_{2}^{j}$ & Grain processing cost at PSF $j$ ( $\$ /$ bushel) \\
\hline$c_{3}, \hat{c}_{3}$ & Unit transportation costs during the harvest season and the off seasons $(\$ /$ bushel*km) \\
\hline$c_{4}, \hat{c}_{4}$ & PHL rates during transportation for the unprocessed and processed grains $(\% / \mathrm{km})$ \\
\hline$\tilde{c}_{4}$ & PHL rate during processing $(\%)$ \\
\hline$c_{5}$ & Grain production cost $(\$ /$ bushel) \\
\hline$c_{0}^{m}(\cdot)$ & Generalized port congestion cost (\$/ bushel*day) \\
\hline$l_{i j}, l_{i k}, l_{i m}$ & Distances from farmer $i$ to PSF $j$, local elevator $k$, and port $m$ \\
\hline$t^{*}$ & Farmers' preferred harvest time \\
\hline $\bar{t}$ & Harvest ending time deadline \\
\hline$t_{e}(\cdot)$ & Critical harvest ending time \\
\hline$\alpha, \beta, \gamma$ & Unit waiting cost at ports, the early harvest penalty, and late harvest penalty ( $\$ /$ bushel*day) \\
\hline$r_{1}, r_{2}$ & Grain arrival rates before and after the preferred harvest time \\
\hline$n$ & Iteration number \\
\hline $\begin{array}{l}v, \pi_{n} \\
\varepsilon\end{array}$ & $\begin{array}{l}\text { Control parameter and step size in the LR algorithm } \\
\text { Stopping criteria }\end{array}$ \\
\hline
\end{tabular}

\section{Decision Variables}

\begin{tabular}{ll}
\hline$p_{j}$ & Purchase price of grains at PSF $j$ (\$/bushel) \\
$Y_{j}$ & Binary variable for PSF construction at $j$ \\
$x_{i j}$ & Amount of grains sold from farmer $i$ to PSF $j$ \\
$x_{i k}$ & Amount of grains sold from farmer $i$ to elevator $k$ \\
$x_{i m}$ & Amount of grains sold from farmer $i$ to export port $k$ \\
$N$ & Total amount of grains shipped to a port \\
$Z_{i}, z_{i}, q, r_{i}$ & Intermedia variables to linearize the stochastic related constraints \\
$\phi$ & Profit of the company \\
$y_{i}$ & Continuous variable to replace $Y_{i}$ in the LR algorithm
\end{tabular}


$\mu_{k}, \rho_{j}, \lambda_{i}, \theta_{i}$

$\chi_{i}^{1}, \chi_{i}^{2}, \chi_{i}^{3} \quad$ Lagrangian multipliers

$\chi_{i}^{4} \xi_{i}, \eta_{j}, \kappa$

1 

$5 \frac{\beta \gamma}{\beta+\gamma} \frac{N}{s}$.

6

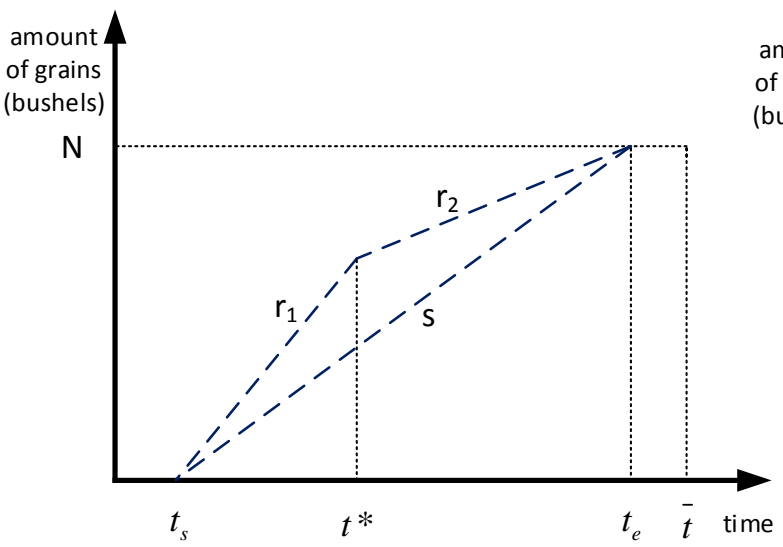

(a) unbinding deadline For the grains harvested at $t$, the generalized cost is given by:

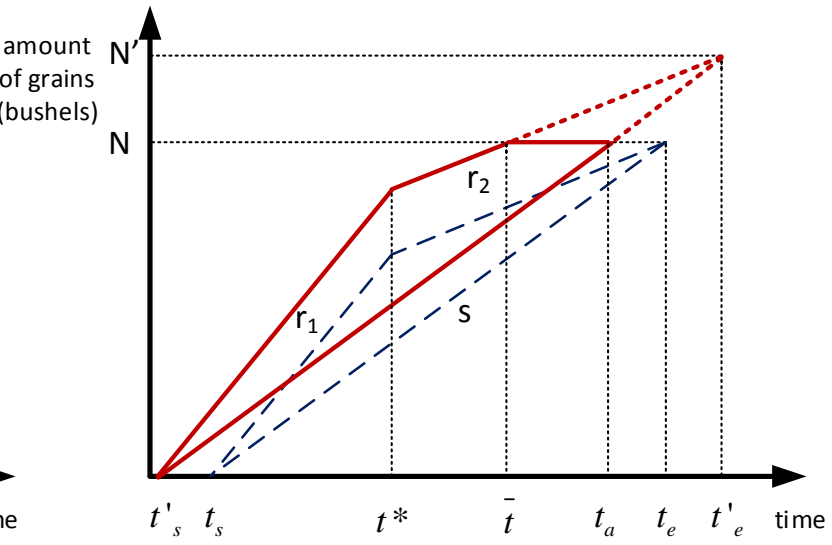

(b) binding deadline

Fig. 5 Harvest time equilibrium

Queue length at the port is $Q(t)=\int_{t_{s}}^{t}(r(u)-s) d u$, where $r(u)$ is the grain arrival rate at time $u$.

$$
C(t)=\alpha T(t)+\beta \max \left\{0, t^{*}-t\right\}+\gamma \max \left\{0, t-t^{*}\right\},
$$

where $T(t)=Q(t) / s$ represents its queuing time since the service rate $s$ is constant. Substituting $T(t)$ into $C(t)$ and calculating its first-order derivative, we can obtain:

$$
\frac{d C(t)}{d t}=0 \Rightarrow\left\{\begin{array}{ll}
\alpha \frac{r(t)-s}{s}-\beta=0 \\
\alpha \frac{r(t)-s}{s}+\gamma=0
\end{array} \quad t \geq t^{*} \quad \Rightarrow r(t)=\left\{\begin{array}{ll}
r_{1}=\frac{\alpha+\beta}{\alpha} s & t<t^{*} \\
r_{2}=\frac{\alpha-\gamma}{\alpha} s & t \geq t^{*}
\end{array} .\right.\right.
$$

21 When $d C(t)=0$, the farmers minimizes the generalized costs for all grains harvest at $t$, and the harvest 22 time equilibrium is achieved. At equilibrium, the generalized cost of grains harvested at $t_{s}$ and $t_{e}$ should 
1 be equal: $\beta\left(t^{*}-t_{s}\right)=\gamma\left(t_{e}-t^{*}\right)$. Noting too that $t_{e}-t_{s}=N / s$, and hence $t_{s}=t^{*}-\frac{\gamma}{\beta+\gamma} \frac{N}{s}$ and $2 t_{e}=t^{*}+\frac{\beta}{\beta+\gamma} \frac{N}{s}$. By substituting $t_{s}$ into $\beta\left(t^{*}-t_{s}\right)$, it can be easily verified that the generalized port 3 congestion cost equals $\frac{\beta \gamma}{\beta+\gamma} \frac{N}{s}$. When $\bar{t} \geq t^{*}+\frac{\beta}{\beta+\gamma} \frac{N}{s}=t_{e}$, the harvest deadline $\bar{t}$ does not affect the equilibrium. The harvest time equilibrium is plotted in Fig. 5a. This completes the proof.

6 Proposition 1. If $\bar{t}<t_{e}=t^{*}+\frac{\beta}{\beta+\gamma} \frac{N}{s}$, the harvest time equilibrium is achieved when grain arrival rate 7 remains $r_{1}=\frac{\alpha+\beta}{\alpha} s$ for $t<t^{*}$ and $r_{2}=\frac{\alpha-\gamma}{\alpha} s$ for $t \geq t^{*}$. The generalized port congestion cost at 8 equilibrium however becomes $c_{0}^{m}(N, \bar{t})=\frac{\alpha \beta}{(\alpha+\beta)} \frac{N}{s}-\frac{\beta(\alpha-\gamma)\left(\bar{t}-t^{*}\right)}{(\alpha+\beta)}$.

Proof: Following the proof for Lemma 1, the grain arrival rates $r(t)$ should remain unchanged to ensure that grains harvested at any time $t$ have the same generalized cost. To ensure that the last batch of grains $N$ should be shipped out at $\bar{t}$, the only way is that arrival curve with the rate of $r_{2}$ shift up such that it passes point $(\bar{t}, N)$ in Fig. 5b. Then, the rest of the arrival curve (with rate $\left.r_{1}\right)$ and the departure curve (with rate $s$ ) must shift accordingly. The quadrilateral formulated by the solid bold lines represents the new harvest time equilibrium with binding $\bar{t}$. We can observe that the grain harvest starts at $t_{s}^{\prime}$ and ends at $\bar{t}$. All grains leave the port bottleneck by $t_{a}$.

To derive $c_{0}^{m}$, we extend the arrival curve (with rate $r_{2}$ ) and departure curve (with rate $s$ ) to intersect at point $\left(t_{e}^{\prime}, N^{\prime}\right)$. The geometry now resembles that of Lemma 1 , so we can get the same equilibrium results $t_{s}^{\prime}=t^{*}-\frac{\gamma}{\beta+\gamma} \frac{N^{\prime}}{s}, t_{e}^{\prime}=t^{*}+\frac{\beta}{\beta+\gamma} \frac{N^{\prime}}{s}$ and the total generalized cost $\frac{\beta \gamma}{\beta+\gamma} \frac{N^{\prime}}{s}$, if only we replace $N$ by $N^{\prime}$ in the corresponding formulas. The total grain departures by time $\bar{t}$ can be calculated as

$$
r_{1}\left(t^{*}-t^{\prime}{ }_{s}\right)+r_{2}\left(\bar{t}-t^{*}\right)=\frac{(\alpha+\beta) s}{\alpha} \frac{\gamma}{\beta+\gamma} \frac{N^{\prime}}{s}+\frac{(\alpha-\gamma) s}{\alpha}\left(\bar{t}-t^{*}\right)=N .
$$

Then we solve $N^{\prime}$ as a function of $N$; i.e.,

$$
N^{\prime}=N \frac{\alpha(\beta+\gamma)}{\theta(\alpha+\beta)}-\frac{s(\beta+\gamma)(\alpha-\gamma)}{\theta(\alpha+\beta)}\left(\bar{t}-t^{*}\right),
$$

and substitute it into the total generalized cost $\frac{\beta \gamma}{\beta+\gamma} \frac{N^{\prime}}{s}$. The results is

$$
c_{0}^{m}(N, \bar{t})=\frac{\alpha \beta}{(\alpha+\beta)} \frac{N}{s}-\frac{\beta(\alpha-\gamma)}{(\alpha+\beta)}\left(\bar{t}-t^{*}\right) .
$$

This completes the proof. 